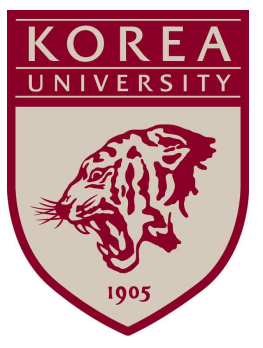

Discussion Paper Series

No. 2003

May 11, 2020

Changes in the Inflation Target and the Comovement between Inflation and the Nominal Interest Rate

\author{
Yunjong Eo Denny Lie
}

The Institute of Economic Research - Korea University

Anam-dong, Sungbuk-ku, Seoul, 136-701, South Korea, Tel: (82-2) 3290-1632, Fax: (82-2) 928-4948

Copyright (C) 2020 IER. 


\title{
Changes in the Inflation Target and the Comovement between Inflation and the Nominal Interest Rate*
}

\author{
Yunjong Eo ${ }^{\dagger} \quad$ Denny Lie ${ }^{\ddagger}$
}

May 11, 2020

\begin{abstract}
Would raising the inflation target require an increase in the nominal interest rate in the short run? We answer this policy question, first analytically in a small-scale New Keynesian model with backward-looking components where a closed-form solution exists, and then in a medium-scale model of Smets and Wouters (2007) calibrated to the U.S. economy. Our analysis shows that the short-run comovement between inflation and the nominal interest rate conditional on changes in the inflation target is more likely to be positive, all else equal, as the monetary authority reacts less aggressively to the deviation of inflation from its target. Meanwhile, features of the model that enhance backward-looking behavior, such as backward price indexation and habit formation in consumption, are shown to reduce the likelihood of the positive comovement. However, our investigations reveal that in both models, this positive comovement or so-called Neo-Fisherism is prevalent across a wide-range of empirically-plausible parameter values. Using the Smets and Wouters model with a zero lower bound constraint (ZLB) on the nominal interest rate, we show that raising the inflation target could be an effective alternative policy framework to reduce the possibility of a binding ZLB constraint and to mitigate the potentially large output loss.
\end{abstract}

JEL Classification: E12; E32; E58; E61;

Keywords: Neo-Fisherism; zero lower bound; inflation expectations; Taylortype rule; hybrid NKPC; hybrid IS curve;

${ }^{*}$ First Draft: July 2018. We thank Saroj Bhattarai, Jinill Kim, Mariano Kulish, Jae Won Lee, James Morley, Woong Yong Park, Dilhan Perera, Dan Rees, and conferences and seminars participants at University of Sydney, Society for Nonlinear Dynamics and Econometrics Conference, Asian Meeting of Econometric Society, Korean Macroeconomics Research Group, Workshop of the Australian Macroeconomics Society (Hobart), KAEA-KIF-KAFA Joint Conference, Western Economic Association International Conference, and Sydney Macro Reading Group Workshop. Andrew Gaffney provided valuable research assistance.

${ }^{\dagger}$ Department of Economics, Korea University, Seoul 02841, South Korea; Email: yunjongeo@korea.ac.kr

${ }^{\ddagger}$ School of Economics, The University of Sydney, NSW 2006, Australia; Email: denny.lie@sydney.edu.au 


\section{Introduction}

\subsection{Overview}

Since the 2007-08 global financial crisis (GFC) and the subsequent Great Recession, nominal interest rates in the U.S. and other developed economies have been persistently lower than before the GFC. The short-term rates have effectively become constrained again by the zero lower bound (ZLB) due to the COVID-19 pandemic. Inflation rates, however, have also continued to be low in these economies and in some inflation targeting economies, have been below the targets. This low inflation, low interest rate environment presents a challenge for central banks. When the short-term nominal interest (policy) rate is low, the central bank's ability to use its conventional monetary policy tool by cutting its policy rate during a recession or an economic downturn is more limited. As shown by Kiley and Roberts (2017), in such an environment the frequency and length of hitting the ZLB on the nominal interest rate are higher, and this may lead to poorer economic performance associated with inflation and economic activity being more volatile and systematically falling short of their desirable levels. To alleviate these concerns, several alternative policy frameworks have been proposed. One such framework is for an inflation targeting central bank to simply raise its inflation target, as proposed by Blanchard, Dell'Ariccia and Mauro (2010), Ball (2014), and Krugman (2014), among others.

Raising the inflation target, especially in a low interest rate environment, in turn poses a substantive policy question: Does raising the target entail an increase in the nominal interest rate? This question has an important policy implication because if a higher inflation target entails a reduction in the nominal rate, policy implemented to avoid the ZLB may, in fact, result in hitting the ZLB. The answer to this question is relatively clear in the long run. From the Fisher equation,

$$
i_{t}=E_{t} \pi_{t+1}+r_{t}
$$

where $i_{t}$ is the nominal interest rate, $r_{t}$ is the real interest rate, and $E_{t} \pi_{t+1}$ is the one-

period ahead expected inflation rate. The nominal interest rate and expected inflation, and hence actual inflation, move together one-for-one in the long run insofar as the classical 
dichotomy holds, i.e., the long-run real interest rate is independent of nominal variables and is solely determined by macroeconomic fundamentals such as the discount factor and longrun output growth. Building on this long-run relationship, Cochrane (2016) and Williamson (2016) argue that a central bank can raise inflation even in the short run by setting a higher interest rate consistent with an inflation target. They dub this property Neo-Fisherism.

In the short run, however, the answer is not so clear-cut. The presence of nominal frictions such as price and wage rigidities complicates the short-run relationship between the inflation target, inflation, and the nominal interest rate. The comovement between inflation and the nominal interest rate may break down, as nominal shocks (e.g., an increase in the inflation target) have short-run effects on the real interest rate.

\subsection{Main findings and contribution}

In this paper, we investigate the Neo-Fisherian property, which we define, following Garín, Lester and Sims (2018), as a positive comovement between the nominal interest rate and inflation conditional on a change in the inflation target. We do this first analytically within a small-scale New Keynesian model, where there exists a closed-form solution, and then numerically in a medium-scale model of the U.S. economy in Smets and Wouters (2007), containing much richer dynamics. We also use the Smets and Wouters model to assess the effectiveness of raising the inflation target in the presence of large contractionary shocks whereby the ZLB on the nominal interest rate may be binding. Our main findings and contributions are summarized as follows.

First, we investigate the relationship between Neo-Fisherism and the monetary policy stance, in conjunction with the deep parameters in the small-scale model involving backwardlooking and forward-looking elements. We show that as the monetary authority reacts more aggressively to the deviation of inflation from its target, inflation and the nominal interest rate are less likely to comove positively following an increase in the inflation target. In addition, a positive comovement is less likely as the degree of backward-lookingness in the model - such as price indexation to past inflation or habit formation in consumption - gets higher. However, we find that the model is most likely to exhibit Neo-Fisherism for a range of reasonable structural parameter values unless the monetary authority reacts to inflation 
in an extremely aggressive manner, close to strict inflation targeting. This is true even under a high degree of backward-lookingness in the model.

The intuition behind this finding can be understood from the Fisher equation (1). When the target is raised, the real interest rate decreases contemporaneously irrespective of the value of the inflation reaction coefficient in the policy rule. When the central bank reacts extremely aggressively to the inflation deviation, e.g., under strict inflation targeting, inflation and expected inflation are largely stabilized around the target level. It follows then, from (1), that the nominal interest rate is less likely to increase in the short run, in line with the reduction in the real rate. Allowing for backward-looking elements in the model also enhances the likelihood of a contemporaneous decrease in the nominal interest rate, as these elements reduce the change in expected inflation and cause a larger decrease in the real interest rate following an increase in the inflation target. On the other hand, when the inflation reaction coefficient is low, e.g., a Taylor-rule coefficient of 1.5, agents expect inflation to be less stabilized, which implies that expected inflation jumps more following an increase in the inflation target. This in turn enhances the possibility of short-run comovement between inflation and the nominal interest rate. Here, the increase in expected inflation is sufficiently high to counteract the decrease in the real interest rate. We find that the upper bound of the inflation reaction coefficient that guarantees Neo-Fisherian results is considerably larger than most reasonable values found for the U.S. and other economies in the literature. Thus, standard New Keynesian models with typical parameterizations of a Taylor-type rule and other standard model equations considered in the literature will most likely exhibit Neo-Fisherism.

Second, we show that our finding above also translates to the Smets and Wouters (SW) model, augmented with an inflation target shock. The SW model has much richer dynamics compared to the small-scale model: it contains rich backward-looking elements such as sticky nominal price and wage settings with indexation to past inflation, habit formation in consumption, investment adjustment costs, and interest-rate smoothing. Our results show that the SW model exhibits Neo-Fisherism over a wide range of empirically-plausible parameter values. Despite the presence of rich backward-looking elements, the positive comovement between inflation and the nominal interest rate is only reversed for an empirically-implausibly 
large value of the inflation reaction coefficient in the policy rule. Conditional on the values of the monetary policy rule parameters reported in Smets and Wouters (2007), even full price indexation to past inflation or full habit formation in consumption cannot break down Neo-Fisherism.

Third, using the SW model with an explicit ZLB constraint on the nominal interest rate, we show that raising the inflation target could be an effective policy tool to mitigate the potentially large output loss arising from a binding ZLB constraint and large contractionary shocks. We illustrate this using a scenario whereby the economy is hit by a series of large, contractionary risk-premium shocks. When the inflation target is kept unchanged at its current level, these shocks cause the ZLB constraint on the nominal rate to be binding for several periods. On the other hand, the ZLB never binds when the target is raised instead. The cumulative output gain of raising the inflation target from $2 \%$ to $4 \%$ per annum is as much as $47 \%$ in our counterfactuals.

\subsection{Related literature}

Our paper is closely related to several recent studies in the literature.

We contribute to resolving the discrepancy between theoretical and empirical findings on Neo-Fisherism in New Keynesian models. ${ }^{1}$ For example, Ireland (2007), Cogley, Primiceri and Sargent (2010), and Castelnuovo (2012) among others find that a highly persistent or a permanent change in the inflation target leads to a short-run positive comovement between inflation and the nominal interest rate, based on estimated models for the U.S. economy with rich backward-looking elements. Fève, Matheron and Sahuc (2010) also find a positive comovement based on an estimated New Keynesian model of euro area. Garín, Lester and Sims (2018) meanwhile argue that a modest, empirically plausible degree of backward-looking behavior in the NKPC (through "rule-of-thumb" price setters) can eliminate Neo-Fisherism using a strict inflation targeting rule, even when the monetary authority raises the inflation target almost permanently. Our first main finding provides an answer on why they reach different conclusions. As we discussed above, the strict inflation targeting rule overstates the

\footnotetext{
${ }^{1}$ For a recent literature focusing on a liquidity trap, see Schmitt-Grohé and Uribe $(2014,2017)$ and Bilbiie (2018).
} 
role of the backward-looking component in the NKPC in breaking down Neo-Fisherism and understates the role of the forward-looking effect in inflation expectations formation.

The finding that strict inflation targeting understates the role of forward-looking elements in inflation expectations formation is also consistent with the implications of Bhattarai, Lee and Park (2014a), who consider a purely forward-looking New Keynesian model. They find that inflation almost always overshoots changes in the inflation target for plausible parameterizations in the literature. Our findings show that allowing for backward-looking components in the model under strict inflation targeting may alter their conclusion. However, regardless of the existence of backward-looking components, the monetary policy stance affects inflation expectations formation in the same way. The inflation overshooting identified by Bhattarai, Lee and Park (2014a) is equivalent to the positive comovement between inflation and the nominal interest rate in our paper, given that the nominal interest rate reacts positively to the inflation gap - the difference between inflation and its target - in the policy rule. More importantly, they show that a stronger reaction to inflation in a Taylor-type rule decreases the response of inflation, implying that Neo-Fisherian results are less likely.

Finally, we also contribute to the literature on alternative monetary policy frameworks to alleviate the potential economic costs associated with the ZLB constraint on the nominal rate in a low natural interest rate $\left(r^{*}\right)$ world. ${ }^{2}$ Blanchard, Dell'Ariccia and Mauro (2010), Ball (2014), and Krugman (2014) argue that raising the inflation target can help avoid frequently hitting the ZLB. We show that raising the inflation target is an effective policy tool in mitigating the potentially large output loss in such an environment in addition to necessitating a short-run increase in the nominal (policy) interest rate, rather than a decrease.

\subsection{Organization}

The rest of this paper is organized as follows. Using a simple, small-scale New Keynesian model, Section 2 analytically studies the relationship between Neo-Fisherism and monetary

\footnotetext{
${ }^{2}$ Three other notable alternative frameworks that have been proposed are price-level targeting (e.g., Gaspar, Smets and Vestin (2010), Bernanke (2017), Williams (2017)), nominal-income targeting (e.g., McCallum and Nelson (1999), Frankel (2013), Williams (2016)), and average inflation targeting (e.g., Nessén and Vestin (2005), Svensson (2019), Eo and Lie (2020)). For other studies on changing the inflation target, see Williams (2016), Rosengren (2018), and Summers, Wessel and Murray (2018).
} 
policy stance as well as several key structural parameters of the model. Section 3 investigates the short-run comovement in the medium-scale model in Smets and Wouters (2007) and assesses the effectiveness of raising the inflation target when the ZLB constraint on the nominal rate is present. Section 4 concludes.

\section{Analysis with a small-scale model}

\subsection{A small-scale New Keynesian model with inflation target ad- justments}

We consider a small-scale New Keynesian model along the line of the textbook model in Galí (2015). This simple model has a rich enough propagation mechanism for our purpose and it allows us to derive a closed-form analytical solution. In particular, we consider a hybrid New Keynesian Phillips curve (NKPC) or hybrid IS curve to examine the interaction between monetary policy stance and the backward-looking element in the model.

The hybrid NKPC equation is given by

$$
\pi_{t}-\tau \pi_{t-1}=\beta E_{t}\left[\pi_{t+1}-\tau \pi_{t}\right]+\kappa y_{t}
$$

where

$$
\kappa=\frac{(1-\theta \beta)(1-\theta)(\sigma+\eta)}{\theta}
$$

$\pi_{t}$ denotes inflation deviation from its steady state, and $y_{t}$ denotes the output gap, defined as the log deviation of output from its natural level. The slope of the NKPC $\kappa$ is a function of structural parameters. Here, $\beta \in(0,1)$ is the discount factor, $\sigma>0$ is the inverse elasticity

of intertemporal substitution (EIS), and $\eta \geq 0$ is the Frisch inverse elasticity of labor supply. As in Calvo (1983) and Yun (1996), a $\theta \in[0,1)$ fraction of the firms are not allowed to optimally adjust their prices at any given period. Hence, they simply index their prices to a weighted average of past gross inflation $\Pi_{t-1}$ and steady-state gross inflation $\bar{\Pi}$, and $\tau$ in (2) is associated with the degree of indexation to $\Pi_{t-1}$ as in Christiano, Eichenbaum and Evans (2005). When $\tau=0$ the NKPC above reduces to a purely forward-looking version. 
The log-linearized version of the hybrid IS curve is the following:

$$
y_{t}=\frac{1}{1+h} E_{t} y_{t+1}+\frac{h}{1+h} y_{t-1}-\sigma^{-1} \frac{1-h}{1+h}\left(i_{t}-E_{t} \pi_{t+1}\right)
$$

where $i_{t}$ is the nominal interest rate deviation from its steady state and $h \in[0,1)$ is the habit parameter. ${ }^{3}$

In terms of monetary policy, the authority adjusts the nominal interest rate according to

$$
i_{t}=\psi_{\pi}\left(\pi_{t}-\pi_{t}^{*}\right)^{4}
$$

and the inflation target is adjusted as follows:

$$
\pi_{t}^{*}=\phi_{\pi^{*}} \pi_{t-1}^{*}+\epsilon_{\pi^{*}, t}
$$

where $\pi_{t}^{*}$ is the inflation target deviation from steady-state inflation, $0<\phi_{\pi^{*}} \leq 1$, and $\epsilon_{\pi^{*}, t} \neq 0$ when the central bank newly adjusts the inflation target. ${ }^{5}$

As a special case of this Taylor-type rule, under strict inflation targeting, the monetary authority puts a high weight on inflation such that $\psi_{\pi} \rightarrow \infty$ in (5), resulting in

$$
\pi_{t}=\pi_{t}^{*}
$$

\subsection{Analytical results with the hybrid NKPC}

In this section we analytically show how the comovement between inflation and the nominal interest rate depends on the inflation gap reaction coefficient in a Taylor-type rule interacting with the backward-looking component in the NKPC. We focus on the backward-looking component in the NKPC here and set $h=0$ in (8), resulting in a standard forward-looking

\footnotetext{
${ }^{3}$ Without loss of generality, we assume away the usual structural shocks, e.g., technology and preference.

${ }^{4}$ This interest-rate rule is assumed to respond to the inflation gap only to be comparable to the strict inflation targeting rule. This specification also helps to find an analytical solution when allowing for a backward-component in the model. We will consider a Taylor-type rule in which the nominal interest rate responds to the output gap in addition to the inflation gap in Section 3.

${ }^{5}$ This autoregressive specification follows that considered in Cogley, Primiceri and Sargent (2010), Del Negro, Giannoni and Schorfheide (2015), and Bhattarai, Lee and Park (2016). When $\phi_{\pi^{*}}=1$, the inflation target is adjusted permanently, and it is equivalent to shifting its long-run target (steady-state inflation).
} 
IS curve

$$
y_{t}=E_{t} y_{t+1}-\sigma^{-1}\left(i_{t}-E_{t} \pi_{t+1}\right) .
$$

We will confirm our findings numerically in a more general setting based on a medium-scale model calibrated to the postwar U.S. economy in the next section.

The inflation reaction coefficient $\psi_{\pi}$ in (5) is restricted to be greater than one to ensure equilibrium determinacy and less than infinity to distinguish a Taylor-type rule from strict inflation targeting. ${ }^{6}$ Under the Taylor-type rule (5), the solutions for inflation and the nominal interest rate are given by

$$
\begin{aligned}
\pi_{t} & =\Phi_{0}(\Theta) \pi_{t}^{*}+\Phi_{1}(\Theta) \pi_{t-1}, \\
i_{t} & =\Gamma_{0}(\Theta) \pi_{t}^{*}+\Gamma_{1}(\Theta) \pi_{t-1},
\end{aligned}
$$

where the coefficients $\Phi_{0}(\Theta), \Phi_{1}(\Theta), \Gamma_{0}(\Theta)$, and $\Gamma_{1}(\Theta)$ are all functions of the structural parameters $\Theta=\left(\phi_{\pi^{*}}, \psi_{\pi}, \tau, \theta, \sigma, \beta, \eta\right) .^{7}$

Using this solution, we analytically characterize the responses of the nominal interest rate conditional on changes in the inflation target with respect to the monetary policy stance $\psi_{\pi}$ when allowing for price indexation to past inflation.

Proposition 1 Under the Taylor-type rule (5) with the hybrid NKPC (2) and the IS curve (8),

(i) the model is least likely to exhibit a comovement between inflation and the nominal interest rate conditional on changes in the inflation target (Neo-Fisherism) under strict inflation targeting compared to a Taylor-type rule, all else equal, and

(ii) inflation always increases in the inflation target.

Proof. See Appendix A.

Proposition 1 above has an important implication for our assessment on the interaction between the backward-looking component in the NKPC and Neo-Fisherism. Garín, Lester

\footnotetext{
${ }^{6}$ Bhattarai, Lee and Park (2014b) analytically show that the Taylor principle, under which the nominal interest rate reacts to more than one-for-one to inflation in the long-run, is a necessary and sufficient condition for determinacy in the New Keynesian model with backward-looking elements. Thus, the lower bound for $\psi_{\pi}$ is set to one in our analysis. For details on the Taylor principle, see Bullard and Mitra (2002).

${ }^{7}$ See Lemma 1 in Appendix A for the solution.
} 
and Sims (2018) argue that a modest degree of backward-looking behavior in the NKPC can eliminate Neo-Fisherism under strict inflation targeting. However, Proposition 1 indicates that assuming strict inflation targeting may overstate the role of the backward-looking component in breaking down Neo-Fisherism, resulting in understating the possibility of NeoFisherism. Furthermore, as strict inflation targeting is a special case of the Taylor-type rule when $\psi_{\pi} \rightarrow \infty$, Proposition 1 implies that Neo-Fisherism can be less likely as $\psi_{\pi}$ gets larger.

The intuition behind Proposition 1 is as follows. Under strict inflation targeting, inflation and expected inflation are completely stabilized at the inflation target level. Under a Taylortype rule, however, agents expect inflation to be less stabilized, i.e., expected inflation and inflation jump more following an increase in the inflation target. All else equal, and given the Fisher equation, this higher jump in expected inflation makes a contemporaneous increase in the nominal interest rate more likely and increases the possibility of Neo-Fisherism. Note that the comovement also depends on the response of the real interest rate. Following the increase in the inflation target, the real interest rate decreases contemporaneously, both under strict inflation targeting and a Taylor-type rule. The occurrence of Neo-Fisherism thus depends on whether the increase in expected inflation is high enough to counteract the decrease in the real interest rate.

We confirm our intuition using the impulse response functions to an inflation target shock for two different values of inflation reaction coefficient, $\psi_{\pi}$. The benchmark case assumes the standard Taylor-rule coefficient of $\psi_{\pi}=1.5$ as in Taylor (1993), while we set a higher value of $\psi_{\pi}=40$ in the second case to mimic strict inflation targeting. We set $\tau=0.5$. This large value of $\tau$ implies a degree of backward-lookingness in the NKPC that is close to the highest value for the U.S. economy reported in Gall and Gertler (1999). ${ }^{8}$ The persistence parameter of the inflation target shock is set to $\phi_{\pi^{*}}=0.95$. Other parameters are set as follows: $\beta=0.99, \sigma=1, \eta=1$, and $\theta=0.7$. Because $\Gamma_{1}$ in (10) is always positive, we check the sign of $\Gamma_{0}$ - the contemporaneous response of the nominal interest rate conditional on a change in the inflation target - to verify Neo-Fisherism in the model.

Panel (a) of Figure 1 shows that in spite of the presence of a significant degree of

\footnotetext{
${ }^{8}$ The degree of backward-lookingness in our NKPC is given by $\gamma_{b}=\tau /(1+\beta \tau)=0.33$, when $\tau=0.5$ and $\beta=0.99$. This is in line with the upper estimate of $\gamma_{b}$ in Gall and Gertler (1999) - see their Table 2.
} 
Figure 1: Impulse response functions to an inflation target shock for different values of the inflation reaction coefficient

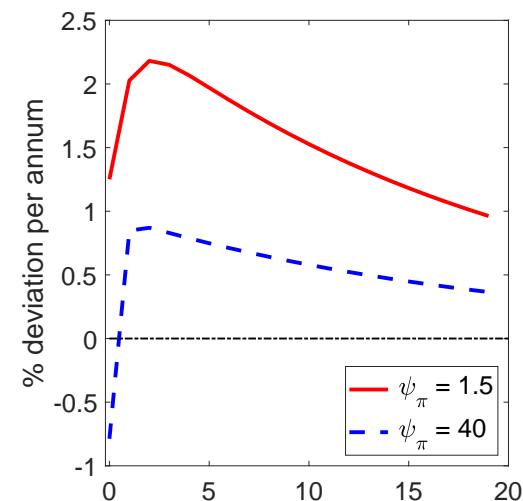

(a) nominal interest rate

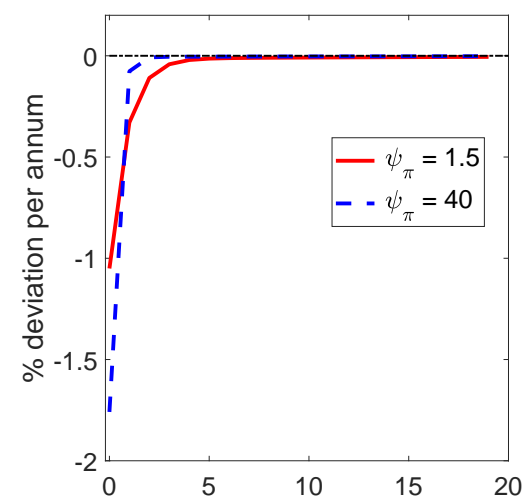

(d) real interest rate

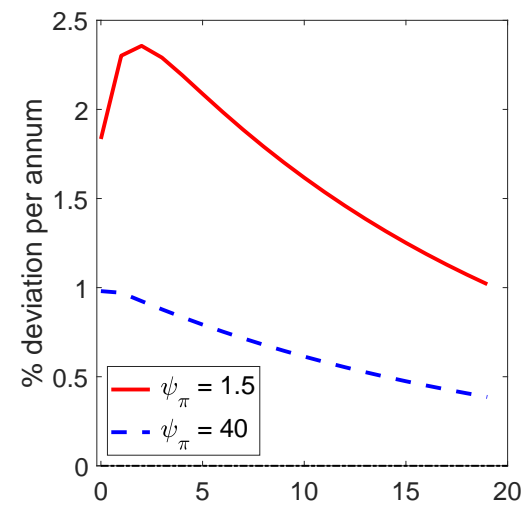

(b) inflation

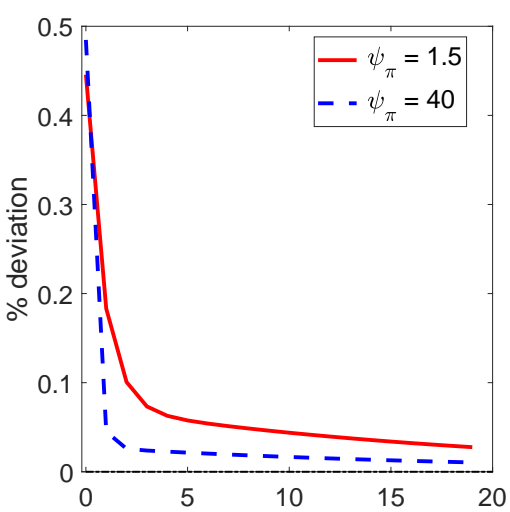

(e) output gap

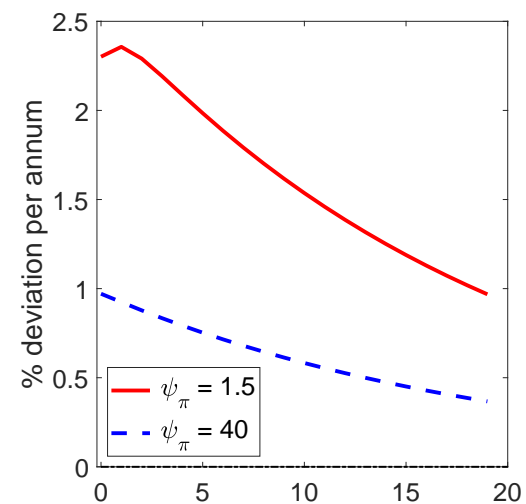

(c) expected inflation $\left(E_{t} \pi_{t+1}\right)$

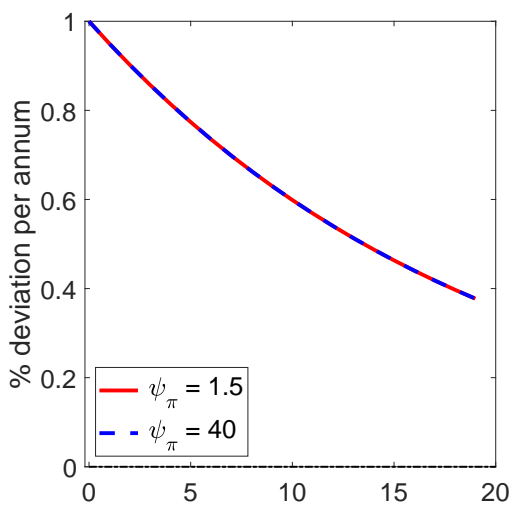

(f) inflation target

Note: The figure plots the impulse response functions of selective variables to a $1 \%$ per annum inflation target shock for different values of the inflation reaction coefficient in a Taylor-type rule $\psi_{\pi}$. The high value of $\psi_{\pi}=40$ is chosen to mimic strict inflation targeting. Other parameters are set to $\tau=0.5, \phi_{\pi^{*}}=0.95$, $\beta=0.99, \sigma=1, \eta=1, \theta=0.7$, and $h=0$.

backward-looking component in the NKPC, the nominal interest rate increases on impact when $\psi_{\pi}=1.5$. On the other hand, when $\psi_{\pi}=40$, raising the inflation target necessitates a contemporaneous decrease in the nominal interest rate. Panels (b) and (c) of Figure 1 confirm that both expected inflation and inflation increase by more when $\psi_{\pi}=1.5$ compared to the case when $\psi_{\pi}=40$. Here, expected inflation rises by $2.3 \%$ on impact following a $1 \%$ increase in the inflation target, while it increases slightly less than the inflation target (by $0.98 \%$ ) when $\psi_{\pi}=40$. Notice that the real interest rate decreases by less on impact 
for smaller $\psi_{\pi}$, which also contributes to the occurrence of Neo-Fisherism when $\psi_{\pi}=1.5$. In sum, the nominal interest rate under $\psi_{\pi}=1.5$ increases by $1.3 \%$ on impact, but under $\psi_{\pi}=40$ it decreases by $0.8 \%$.

The implication that strict inflation targeting may understate the forward-looking effect is consistent with the finding in Bhattarai, Lee and Park (2014a), who consider a purely forward-looking New Keynesian model and focuses on the inflation dynamics with the same monetary policy rule as ours. They find that inflation almost always overshoots the inflation target for reasonable parameterizations in the literature. More importantly, they show that a stronger reaction to inflation in a Taylor-type rule decreases the response of inflation to the inflation target shock. ${ }^{9}$ While their model lacks any backward-looking component, the key intuition is applicable to our analytical findings. In a way, strict inflation targeting understates the role of the forward-looking element and overstates the role of the backwardlooking element in the NKPC in forming inflation expectations.

We next examine how the inflation reaction coefficient $\psi_{\pi}$ affects the Neo-Fisherism region across the parameter space of $\left(\tau, \phi_{\pi^{*}}\right)$, using the same values of $\psi_{\pi}$ above. Other parameter values are set as noted previously. Figure 2 shows that the Neo-Fisherian region is markedly smaller under $\psi_{\pi}=40$. In contrast, under the standard Taylor-rule coefficient of $\psi_{\pi}=1.5$, even with a completely backward-looking $\operatorname{NKPC}(\tau=1)$, there is a positive comovement between inflation and the nominal interest rate as long as the persistence of the inflation target shock is roughly greater than 0.83. This corresponds to a half-life of the inflation target shock of only 3.7 quarters for the model to exhibit Neo-Fisherism.

\subsection{Analytical results with the hybrid IS curve}

The analysis now focuses on the role of the backward-looking component in the IS curve in leading to the comovement. To simplify the analysis and permit an analytical solution, we set $\tau=0$ in the NKPC (2), resulting in a purely forward-looking version,

$$
\pi_{t}=\beta E_{t} \pi_{t+1}+\kappa y_{t} .
$$

\footnotetext{
${ }^{9}$ See Propositions 1 and 2 in Bhattarai, Lee and Park (2014a) for more details.
} 
Figure 2: Hybrid NKPC and Monetary policy: the Neo-Fisherian region in the $\left(\tau, \phi_{\pi^{*}}\right)$ parameter space

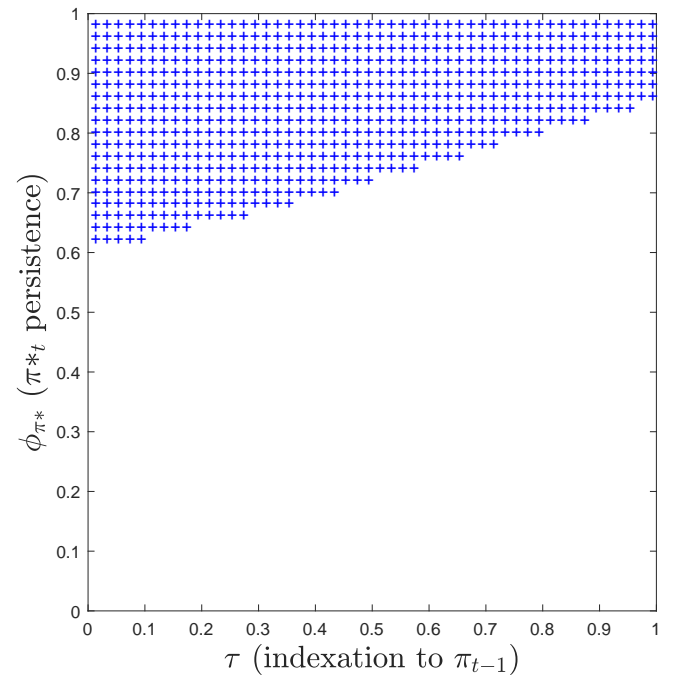

(a) $\psi_{\pi}=1.5$

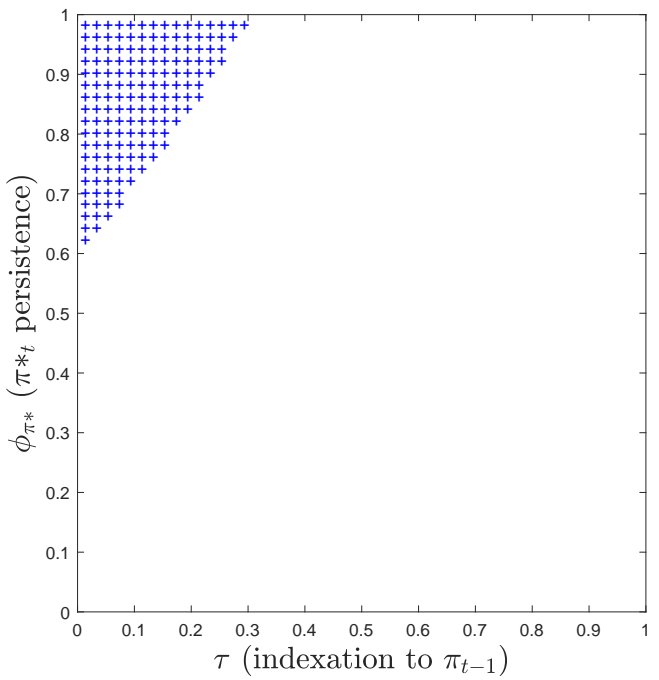

(b) $\psi_{\pi}=40$

Note: The sign of ' + ' indicates a pair of $\left(\tau, \phi_{\pi^{*}}\right)$ values associated with the positive comovement between inflation and the nominal interest rate conditional on a change in the inflation target. The parameter $\psi_{\pi}$ is the reaction coefficient to the inflation gap in the Taylor-type rule. The high value of $\psi_{\pi}=40$ is chosen to mimic strict inflation targeting. Other parameters are set to $\beta=0.99, \sigma=1, \eta=1, \theta=0.7$, and $h=0$.

Based on the analytical solution, we arrive at the following proposition. ${ }^{10}$

Proposition 2 Under the Taylor-type rule (5) with the hybrid IS curve (4) and the NKPC (11),

(i) the model is least likely to exhibit a comovement between inflation and the nominal interest rate conditional on changes in the inflation target (Neo-Fisherism) under strict inflation targeting compared to a Taylor-type rule, all else equal, and

(ii) inflation always increases in the inflation target.

Proof. See Appendix A.

The intuition and explanation associated with Proposition 1 apply to Proposition 2. The increase in the inflation target lowers the real interest rate. Habit formation in consumption makes the output gap less responsive to a given decrease in the real interest rate, resulting in

\footnotetext{
${ }^{10}$ The analytical solution is of a similar form to (9) and (10).
} 
Figure 3: Hybrid IS curve and monetary policy stance: the Neo-Fisherian region in the $\left(\tau, \phi_{\pi^{*}}\right)$ parameter space

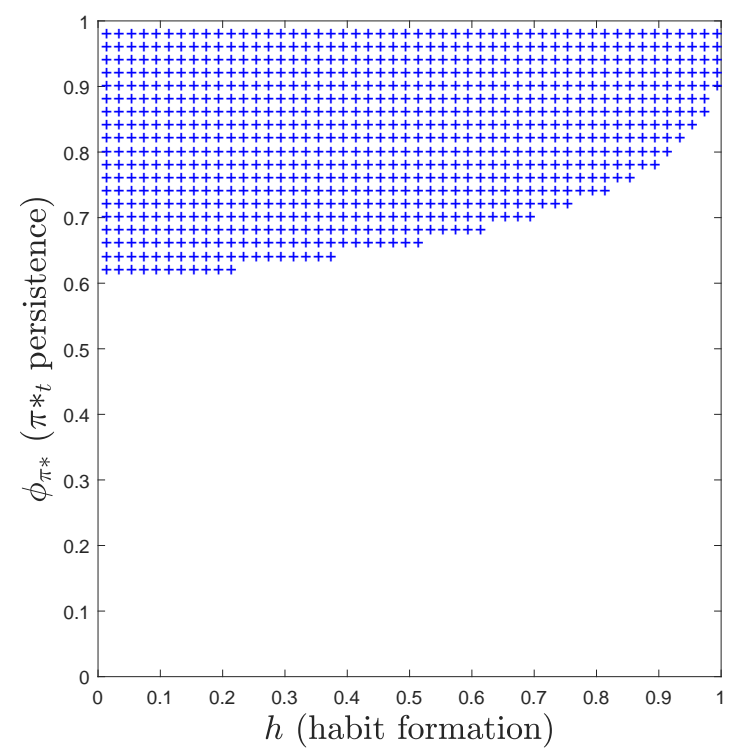

(a) $\psi_{\pi}=1.5$

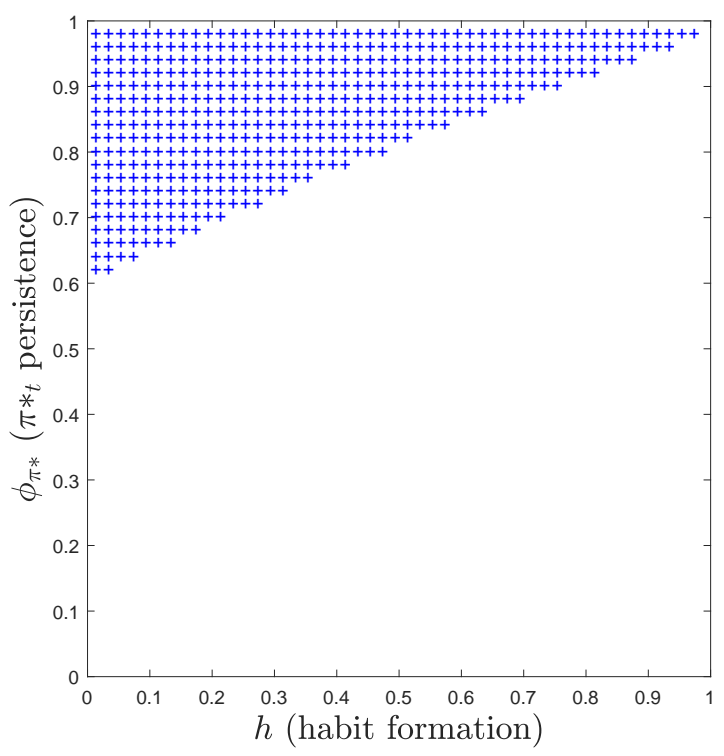

(b) $\psi_{\pi}=40$

Note: The sign of ' + ' indicates a pair of $\left(h, \phi_{\pi^{*}}\right)$ values associated with the positive comovement between inflation and the nominal interest rate conditional on a change in the inflation target. The parameter $\psi_{\pi}$ is the reaction coefficient to the inflation gap in the Taylor-type rule. The high value of $\psi_{\pi}=40$ is chosen to mimic strict inflation targeting. Other parameters are set to $\beta=0.99, \sigma=1, \eta=1, \theta=0.7$, and $\tau=0$.

a weaker jump in inflation through the NKPC. Thus, the nominal interest rate in the model with habit formation reacts less compared to the model with a forward-looking IS curve. The effect of habit formation on inflation dynamics is then amplified when the central bank reacts strongly to the inflation gap, as previously shown in the hybrid NKPC case. Figure 3 confirms the proposition with two different values of $\psi_{\pi}=1.5$ and $\psi_{\pi}=40$ and shows that the Neo-Fisherian region shrinks as the degree of habit formation in consumption gets larger. The positive comovement is also less likely for a higher $\psi_{\pi}$.

\subsection{The NKPC slope and elasticity of intertemporal substitution}

This section examines how other structural parameters affect the comovement. Bhattarai, Lee and Park (2014a) find that using a purely forward-looking New Keynesian model inflation responds more than one-for-one to changes in the inflation target (i.e., the nominal interest 
rates increases given the Taylor-type rule (5)) if prices are sufficiently flexible, while Garín, Lester and Sims (2018) show that the New Keynesian model with a hybrid NKPC under strict inflation targeting is more likely to exhibit Neo-Fisherism the more flexible are prices and the higher is the EIS. We investigate whether these findings are still valid when considering a more general model with the backward-looking components in the NKPC and IS curve.

Under the Taylor-type rule (5) with the hybrid NKPC (2) and the hybrid IS curve (4), Figure 4 graphically illustrates the positive comovement for the parameter space of $(\tau, h)$ with two different values of the Calvo parameter, $\theta=0.7$ (benchmark) and $\theta=0.85$, and two different degrees of monetary policy aggressiveness, $\psi_{\pi}=1.5$ and $\psi_{\pi}=40$. The higher value of $\theta$ implies that prices are stickier, resulting in a flatter NKPC slope of $\kappa=0.06$, as opposed to $\kappa=0.26$ in the benchmark case. ${ }^{11}$ All other parameters are set as previously. Compared to the benchmark case, the flatter NKPC slope shrinks the Neo-Fisherian region. In addition, similar to the benchmark case, the model is less likely to exhibit Neo-Fisherism as the value of $\tau$ and/or $h$ increases or as the central bank reacts to the inflation gap more aggressively.

The finding in Figure 4 shares similar intuition and implication as in Propositions 1 and 2. A higher degree of backward-lookingness in the NKPC or in the IS curve makes inflation and the output gap less responsive on impact and reduces the Neo-Fisherian region. Similarly, as the slope of the NKPC gets flatter (i.e., prices are stickier), inflation is less responsive to a given change in the output gap.

Following the same logic, the output gap is less sensitive to the real interest rate as the EIS gets lower, implying a smaller likelihood of Neo-Fisherism. ${ }^{12}$ Figure 5 confirms this prediction using two different values of the EIS: $\sigma^{-1}=1$ (benchmark) and $\sigma^{-1}=0.2 .{ }^{13}$ Compared to the benchmark case, the model is less likely to exhibit a comovement between

\footnotetext{
${ }^{11}$ The flattening of the Phillips curve in the U.S. and other advanced economies since the early 1980s has been documented in various studies, for example, Roberts (2006), Kuttner and Robinson (2010), and Blanchard (2016). See Eo and Lie (2019) for its welfare implications.

${ }^{12}$ The increase in the EIS also reduces the slope of the NKPC as presented in (3), making inflation less responsive to the change in the output gap. Thus, two effects offset each other and the net effect of changes in the EIS depends on a model specification. However, in the benchmark model we find that $\frac{\partial \kappa \sigma^{-1}}{\partial \sigma^{-1}}>0$ where $\kappa=\frac{(1-\theta \beta)(1-\theta)(\sigma+\eta)}{\theta}$ as also shown in Figure 5 .

${ }^{13}$ The EIS in the literature varies greatly, ranging from below 0.1 in Hall (1988) to $0.8 \sim 1$ in Kydland and Prescott (1982).
} 
Figure 4: NKPC slope and monetary policy stance: the Neo-Fisherian region in the $(\tau, h)$ parameter space under the Taylor-type rule

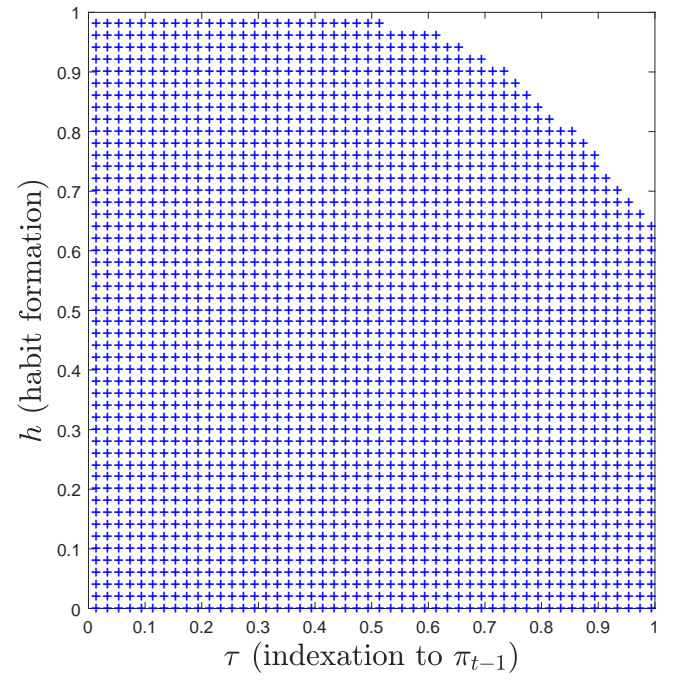

(a) $\theta=0.70(\kappa=0.26)$ and $\psi_{\pi}=1.5$

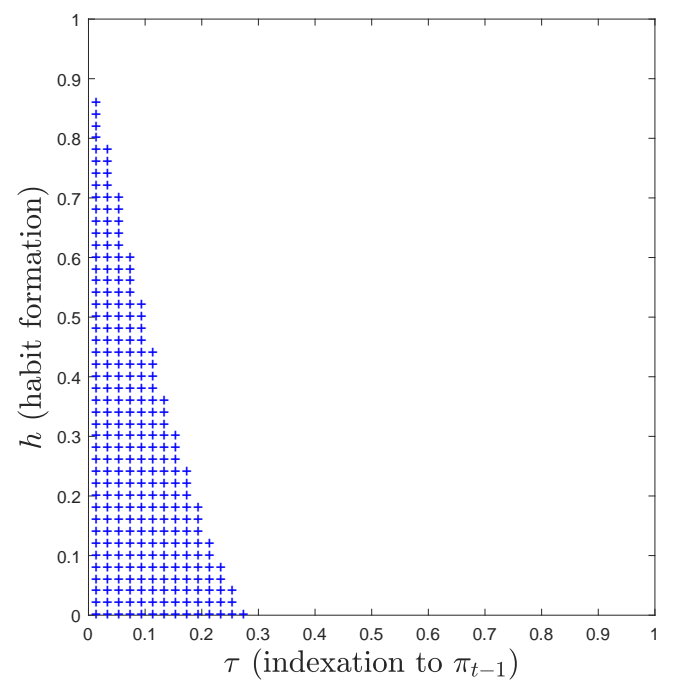

(c) $\theta=0.70(\kappa=0.26)$ and $\psi_{\pi}=40$

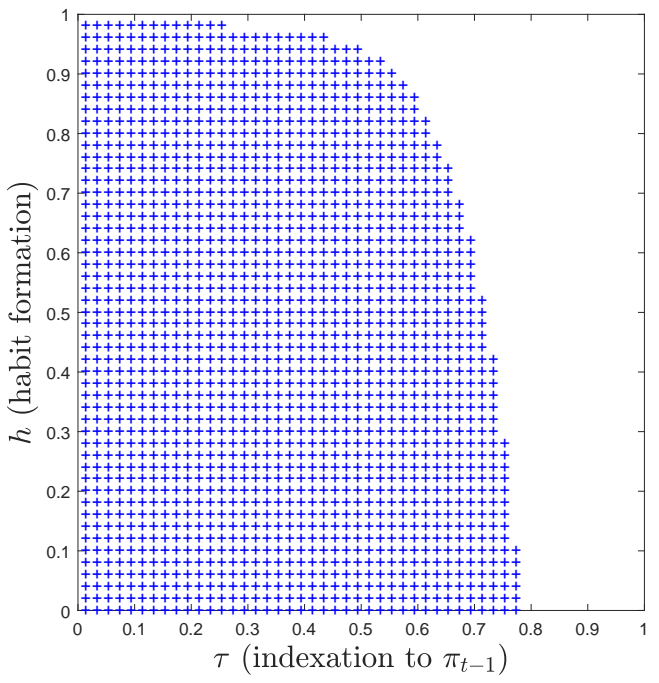

(b) $\theta=0.85(\kappa=0.06)$ and $\psi_{\pi}=1.5$

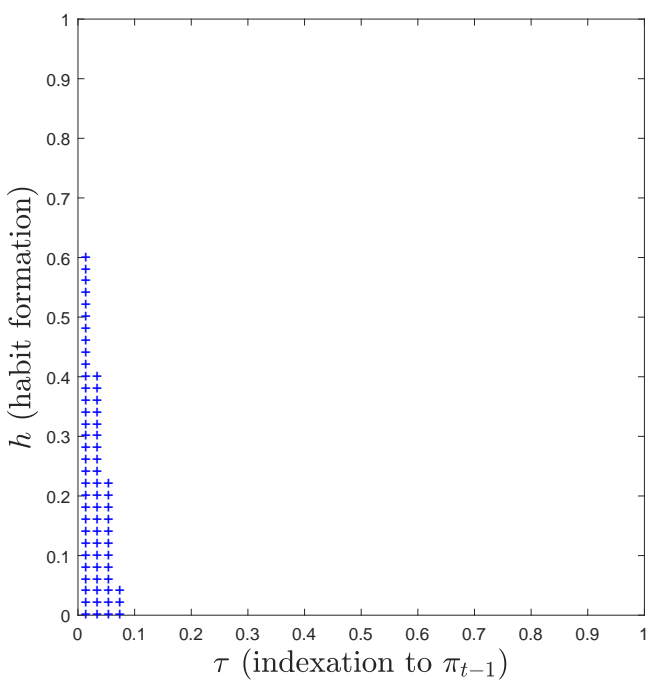

(d) $\theta=0.85(\kappa=0.06)$ and $\psi_{\pi}=40$

Note: The sign of ' + ' indicates a pair of $(\tau, h)$ values associated with the positive comovement between inflation and the nominal interest rate conditional on a change in the inflation target. The Calvo parameter $\theta$ is inversely related to the slope of the NKPC $\kappa$ in (2). We set $\beta=0.99, \sigma=1$, and $\eta=1$.

inflation and the nominal interest rate conditional on changes in the inflation target for a smaller value of the EIS (i.e., as $\sigma^{-1}$ in (8) gets smaller). 
Figure 5: EIS and NKPC slope: the Neo-Fisherian region in the $(\tau, h)$ parameter space under the Taylor-type rule

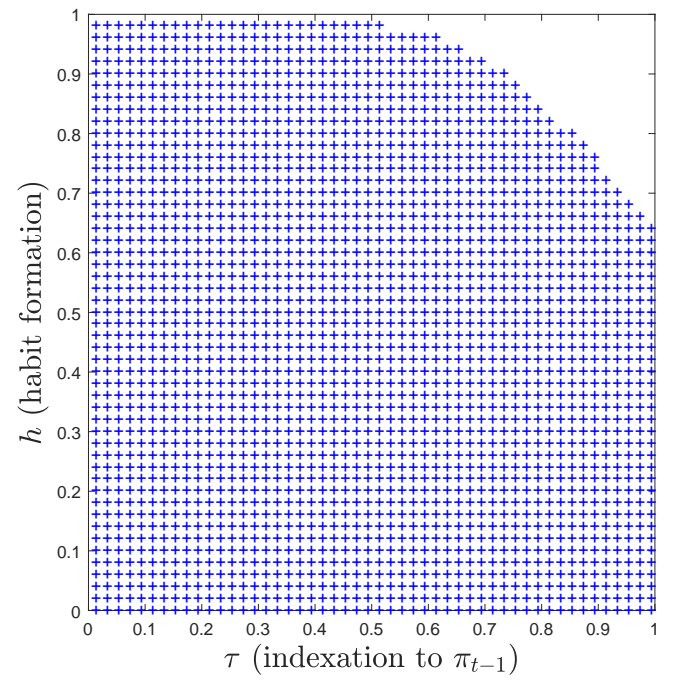

(a) $\theta=0.70(\kappa=0.26)$ and $\sigma^{-1}=1$

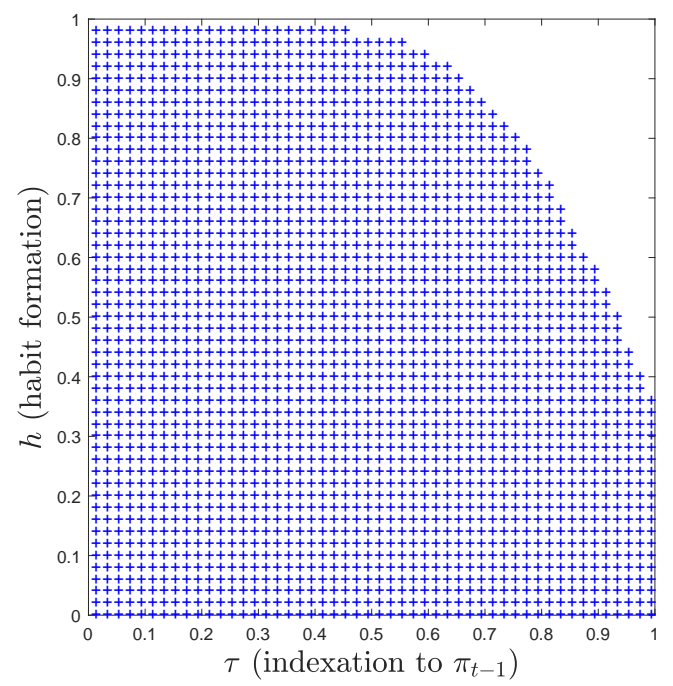

(c) $\theta=0.70(\kappa=0.26)$ and $\sigma^{-1}=0.2$

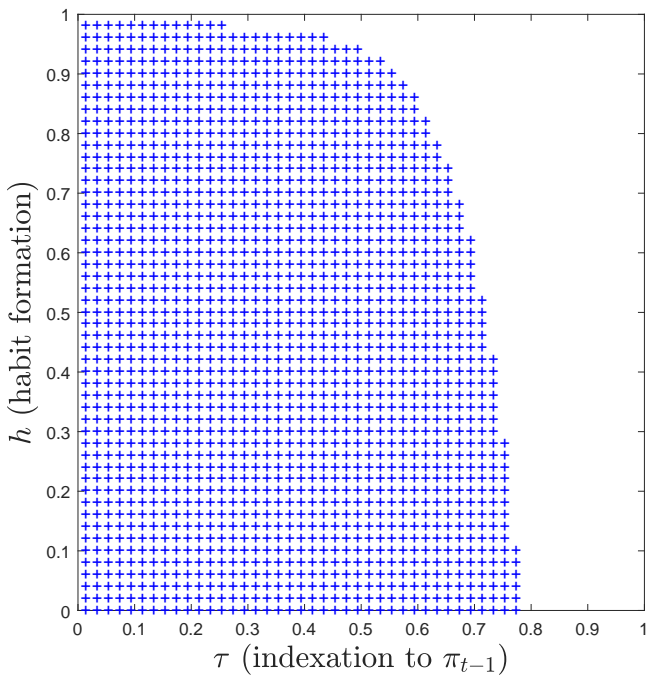

(b) $\theta=0.85(\kappa=0.06)$ and $\sigma^{-1}=1$

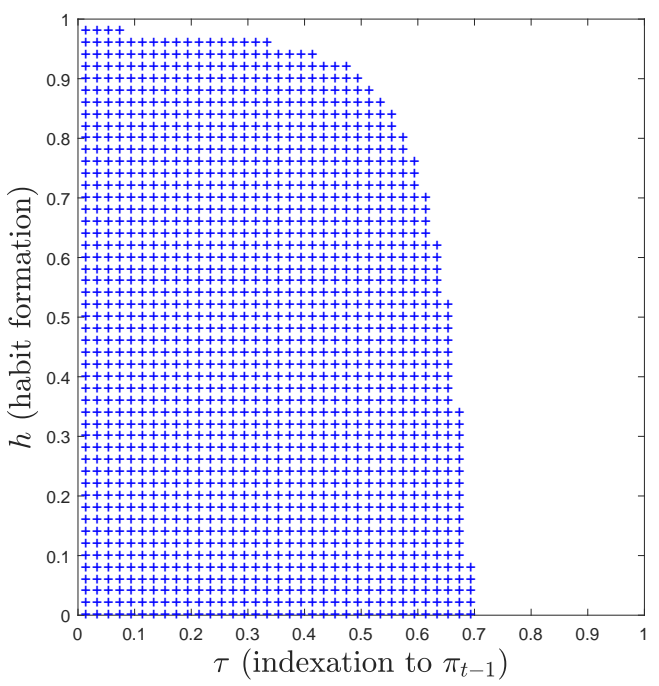

(d) $\theta=0.85(\kappa=0.06)$ and $\sigma^{-1}=0.2$

Note: The sign of ' + ' indicates a pair of $(\tau, h)$ values associated with the positive comovement between inflation and the nominal interest rate conditional on a change in the inflation target. The Calvo parameter $\theta$ is inversely related to the slope of the NKPC $\kappa$ in (2). We set $\psi_{\pi}=1.5, \beta=0.99$, and $\eta=1$. 


\section{The comovement and the effectiveness of raising the inflation target in a medium-scale model}

Our analytical finding in Section 2 that a reasonably-parameterized small-scale New Keynesian model with a hybrid NKPC, a hybrid IS curve, and a Taylor-type rule is likely to exhibit Neo-Fisherism naturally raises a question: Does the finding still apply in a larger-scale model with richer dynamics? In this section, we answer this question using the Smets and Wouters (2007) model, augmented with an inflation target process. We also use the model to assess the effectiveness of raising the inflation target in an environment where the ZLB constraint on the nominal interest rate is potentially binding.

\subsection{The Smets and Wouters (2007) model with inflation target adjustments}

We augment the Smets and Wouters (SW) model by assuming that the monetary authority can adjust its inflation target in a persistent manner, following the process as in (6):

$$
\hat{\pi}_{t}^{*}=\phi_{\pi^{*}} \hat{\pi}_{t-1}^{*}+\hat{\varepsilon}_{\pi^{*}, t}
$$

$\hat{\varepsilon}_{\pi^{*}, t}$ is the inflation target shock, with $\hat{\varepsilon}_{\pi^{*}, t} \neq 0$ when the central bank newly adjusts the inflation target. We also modify the monetary policy rule accordingly to

$$
\hat{r}_{t}=\rho \hat{r}_{t-1}+(1-\rho)\left[r_{\pi}\left(\hat{\pi}_{t}-\hat{\pi}_{t}^{*}\right)+r_{y}\left(\hat{y}_{t}-\hat{y}_{t}^{p}\right)+r_{\Delta y}\left\{\left(\hat{y}_{t}-\hat{y}_{t}^{p}\right)-\left(\hat{y}_{t-1}-\hat{y}_{t-1}^{p}\right)\right\}\right]+\hat{\varepsilon}_{t}^{r},
$$

where all the hatted variables are in terms of their deviations from the steady state or the balanced growth path. In the above - and throughout this section-we closely follow the variable and parameter naming convention in Smets and Wouters (2007): $\hat{r}_{t}$ is the nominal interest (policy) rate, $\hat{\pi}_{t}$ is inflation, $\hat{y}_{t}$ is output, $\hat{y}_{t}^{p}$ is natural output level, $\hat{\varepsilon}_{t}^{r}$ is the monetary policy shock, $\rho$ is the interest-rate smoothing parameter, and $r_{\pi}, r_{y}$ and $r_{\Delta y}$ are feedback coefficients. The only difference between (13) and the policy rule in the original SW model is that the inflation target $\hat{\pi}_{t}^{*}$ is constant in the latter. For a more detailed description of 
the SW model, we refer the reader to Appendix B and their paper.

Unless otherwise mentioned, we set the parameter values of the model to the posterior mode estimates in Smets and Wouters (2007) for the sample period of 1984Q1-2004Q4 (see their Table 5 or Table B.1 presented in Appendix B). Note that unlike in the small-scale model in Section 2, the SW model has much richer dynamics with various forward- and backward-looking elements, which means we cannot simply rely on the contemporaneous response of the nominal rate to investigate its comovement with inflation when the monetary authority adjusts the inflation target.

\subsection{Impulse response functions to changes in the inflation target}

To assess how changes in the inflation target affect various macroeconomic variables in the SW model, Figure 6 plots the impulse responses to a $1 \%$ per-annum inflation target shock. We consider two values of inflation target persistence- $\phi_{\pi^{*}}=0.95$ (benchmark) and $\phi_{\pi^{*}}=0.85$ - which correspond to the half life of the shock of 13.5 and 4.3 quarters, respectively. The benchmark value of $\phi_{\pi^{*}}=0.95$ is lower than the value for the postwar U.S. economy set in various studies in the literature (e.g. Cogley, Primiceri and Sargent (2010), Del Negro, Giannoni and Schorfheide (2015), and Bhattarai, Lee and Park (2016)). ${ }^{14}$

Under the benchmark parameterization with $\phi_{\pi^{*}}=0.95$, inflation increases on impact by more than $1 \%$ per annum. This positive inflation gap - the gap between inflation and the inflation target - is due to a higher expected inflation, caused by the persistent (but temporary) increase in the inflation target. Inflation remains elevated well above the initial target even after 20 quarters. The real interest rates are temporarily lower as inflation expectations rise, leading to a prolonged period of higher (positive) output gaps. A higher inflation target is thus associated with a higher output level in the short run, consistent with the VAR evidence in De Michelis and Iacoviello (2016) for both Japanese and U.S. economies. ${ }^{15}$ Associated with the increase in the inflation target, the monetary authority needs to contemporaneously raise the nominal interest rate by almost $0.3 \%$ per annum on

\footnotetext{
${ }^{14}$ Cogley, Primiceri and Sargent (2010) and Bhattarai, Lee and Park (2016) calibrate $\phi_{\pi^{*}}$ to 0.995, while Del Negro, Giannoni and Schorfheide (2015) find a posterior mode of 0.99.

${ }^{15}$ For the VAR analysis applied to U.S. data, see Appendix A in their paper.
} 
Figure 6: Smets and Wouters model: Impulse responses to an inflation target shock for different values of inflation target persistence
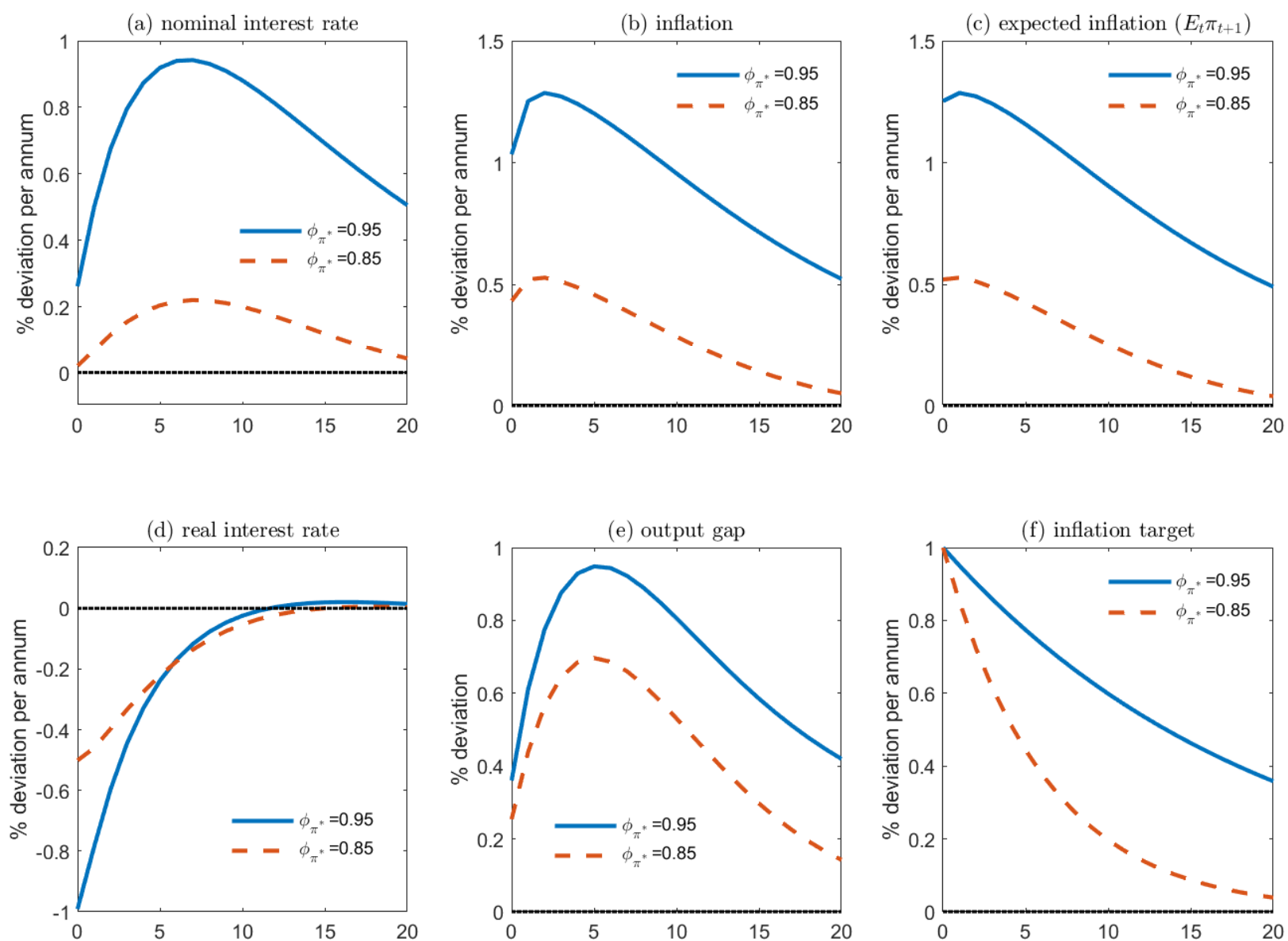

Note: The size of the inflation target shock is $1 \%$ per annum at period $0 . \phi_{\pi^{*}}=0.95$ and 0.85 correspond to the half-life of the shock of 13.5 and 4.3 quarters, respectively. All other parameter values are set to the posterior mode estimates in Smets and Wouters (2007) for the sample period of 1984Q1-2004Q4.

impact, with a hump-shaped response thereafter. The main finding is that there is a positive comovement between inflation and the nominal interest rates throughout the periods.

When $\phi_{\pi^{*}}=0.85$ instead, even though the nominal interest rate only increases slightly on impact, it still positively comoves with inflation throughout the periods. A much lower increase in expected inflation causes inflation to increase by only $0.5 \%$ per annum in this case. Thus, even with this relatively short half-life of 4.3 quarters, we observe Neo-Fisherism: raising the inflation target necessitates a short-run increase in the nominal (policy) interest rate. 
Figure 7: Smets and Wouters model: Impulse responses to an inflation target shock for different values of selective parameters
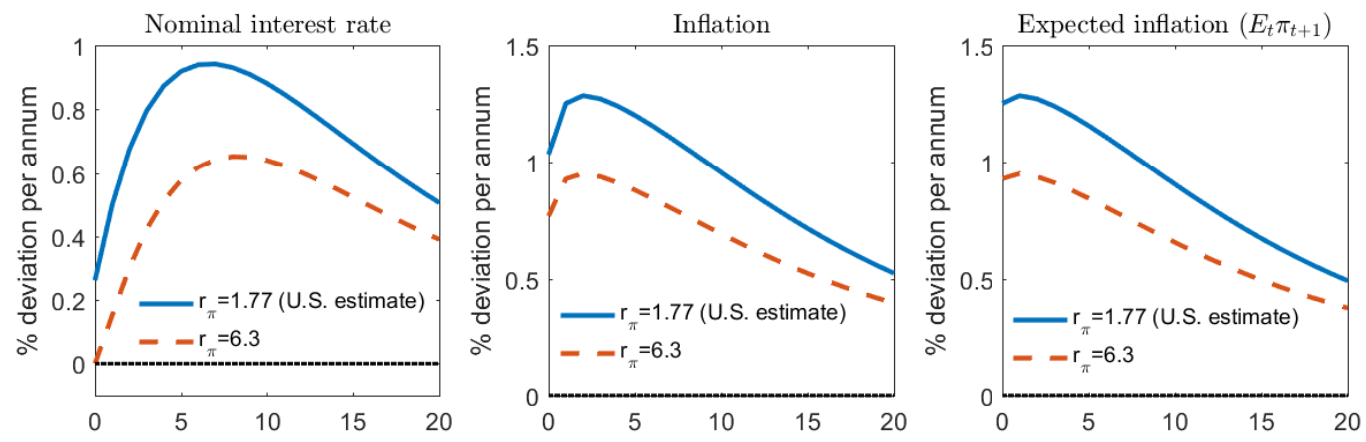

(a) Inflation reaction coefficient
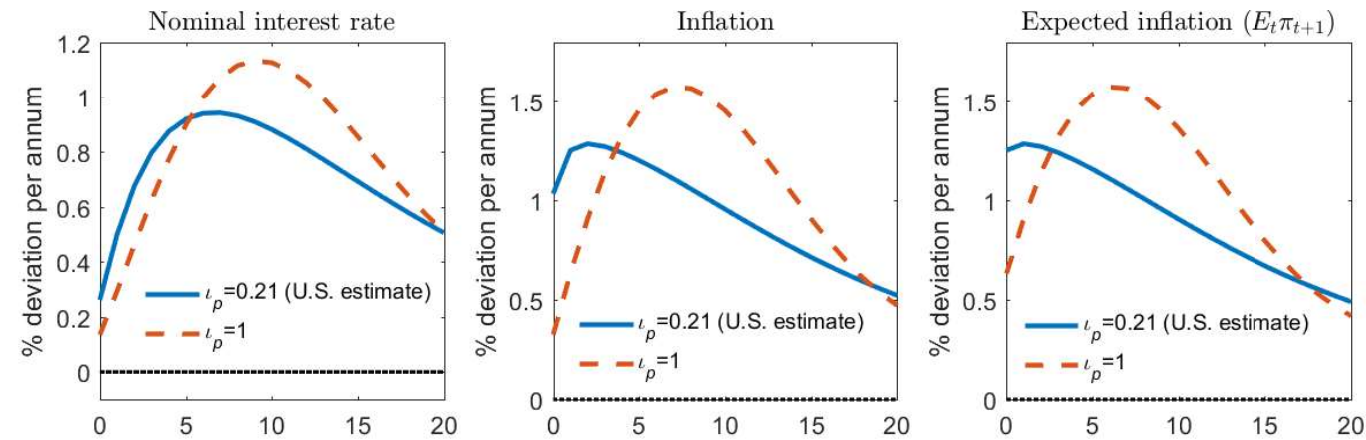

(b) NKPC price-indexation parameter
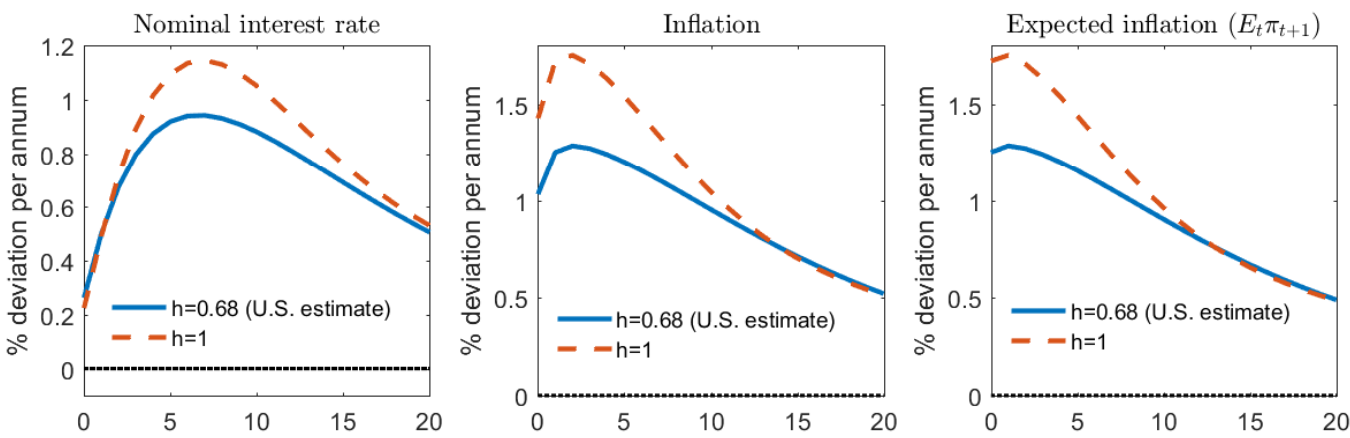

(c) Habit parameter

Note: The size of the inflation target shock in all cases is $1 \%$ per annum at period 0 with $\phi_{\pi^{*}}=0.95$. In Panel (a), $r_{\pi}=6.3$ is the largest $r_{\pi}$ at which the contemporaneous response of the nominal interest rate is non-negative. In Panel (b),$\iota_{p}=1$ is the highest possible indexation value (degree of backwardlookingness in the NKPC). In Panel (c), $h=1$ is the highest possible value of the habit parameter. All other parameter values are set to the posterior mode estimates in Smets and Wouters (2007) for the sample period of 1984Q1-2004Q4. 
In Figure 7 we investigate how the comovement between inflation and the nominal interest rate is affected by the monetary policy stance, i.e., the inflation reaction coefficient $r_{\pi}$, the price indexation parameter $\iota_{p}$ that governs the degree of backward-lookingness in the NKPC, and the external habit parameter $h$ that governs the degree of backward-lookingness in the IS curve. We focus on the responses of the nominal rate, inflation, and expected inflation. In all three cases, the size of the inflation target shock is $1 \%$ per annum at period 0 , with $\phi_{\pi^{*}}=0.95$.

Panel (a) of Figure 7 shows that inflation expectations jump by less for the higher $r_{\pi}$, making a positive comovement less likely. This result is consistent with Propositions 1 and 2 in Section 2. Under the SW model, a positive comovement still occurs as long as $r_{\pi} \leq 6.3$. This threshold is higher than all known estimates of the parameter for the U.S. economy. When $r_{\pi}>6.3$, the nominal interest rate decreases on impact, even though the comovement may still be positive in subsequent periods.

The effect of a higher degree of backward-lookingness in the NKPC is depicted in Panel (b) of Figure 7. Here, even with the highest possible degree of indexation $\left(\iota_{p}=1\right)$, there is still a positive comovement between inflation and the nominal rate. Even though the nominal interest rate increases by less in the case of $\iota_{p}=1$ - consistent with that in the small-scale model - it may increase by more in the later periods, mirroring the responses of inflation and expected inflation. This owes to the fact that the SW model has much richer backwardlooking dynamics.

In Panel (c) of Figure 7, we observe that increasing the value of the habit parameter in the household preference from $h=0.68$ to its maximum value of $h=1$ still implies a positive comovement. The nominal interest rate increases by less on impact - though only barely-when $h=1$ (a more backward-looking IS curve), consistent with our finding in Section 2. Interestingly, both inflation and expected inflation jump by more in the case of $h=1$ despite a more backward-looking environment, implying lower real interest rates (not shown).

In Appendix C, we also examine how the NKPC slope (the Calvo price parameter) and the EIS affect the comovement in the SW model. We find that-consistent with the findings in Figures 4 and 5 in Section 2-the SW model is less likely to exhibit Neo-Fisherism as 
prices are stickier (the NKPC slope is flatter) and the EIS is lower. Despite the alternative parameterizations, however, the SW model still generates a positive comovement between inflation and the nominal interest rate conditional on changes in the inflation target.

\subsection{Raising the inflation target and the zero lower bound on the nominal interest rate}

Having established that the medium-scale model in Smets and Wouters (2007) exhibits Neo-Fisherism for a wide range of parameter values, we now use the model to assess the effectiveness of raising the inflation target when the ZLB on the nominal interest rate is potentially binding.

We suppose a scenario where the economy is hit by a series of 4-standard deviation risk-

premium shocks for five consecutive periods (quarters 1-5). In the SW model, the exogenous risk-premium process follows

$$
\hat{\varepsilon}_{t}^{b}=\rho_{b} \hat{\varepsilon}_{t-1}^{b}+\eta_{t}^{b}
$$

where $\eta_{t}^{b} \sim$ i.i.d.N $\left(0, \sigma_{b}^{2}\right)$ is the risk-premium shock. This shock directly affects the con-

sumption Euler equation (the IS curve) and the unit price of capital $\hat{Q}_{t}$ (Tobin's Q) through the relationships

$$
\begin{aligned}
\hat{c}_{t}= & {\left[\frac{h / \gamma}{1+h / \gamma}\right] \hat{c}_{t-1}+\left[\frac{1}{1+h / \gamma}\right] E_{t} \hat{c}_{t+1}-\left[\frac{1-h / \gamma}{\sigma(1+h / \gamma)}\right]\left(\hat{r}_{t}-E_{t} \hat{\pi}_{t+1}-\hat{\varepsilon}_{t}^{b}\right) } \\
& +\left[\frac{(\sigma-1) \theta_{l c}}{\sigma(1+h / \gamma)}\right]\left(\hat{L}_{t}-E_{t} \hat{L}_{t+1}\right)
\end{aligned}
$$

and

$$
\hat{Q}_{t}=-\left(\hat{r}_{t}-E_{t} \hat{\pi}_{t+1}-\hat{\varepsilon}_{t}^{b}\right)+\left[\frac{\bar{r}^{k}}{\bar{r}^{k}+(1-\delta)}\right] E_{t} \hat{r}_{t+1}^{k}+\left[\frac{(1-\delta)}{\bar{r}^{k}+(1-\delta)}\right] E_{t} \hat{Q}_{t+1}
$$

where $\hat{c}_{t}$ is aggregate consumption, $\hat{L}_{t}$ is aggregate labor, and $\hat{r}_{t}^{k}$ is the rental rate of capital. The parameters $h, \gamma, \sigma, \delta, \bar{r}^{k}$, and $\theta_{l c}$ denote habit, trend productivity growth, inverse of EIS, capital depreciation rate, steady-state rental rate of capital, and steady-state labor income to consumption ratio, respectively. Risk-premium shocks thus affect the intertem- 
poral margin of consumption and investment. All else equal, a contractionary risk-premium shock $\left(\hat{\varepsilon}_{t}^{b}<0\right)$ reduces current consumption and-through a decrease in the unit price of capital - investment. This shock is akin to a net worth shock in financial accelerator models à la Bernanke et al. (1999).

Our choice of risk-premium shocks is motivated by the findings in Furlanetto and Groshenny (2016) and Kulish, Morley and Robinson (2017) of the occurrence of large contractionary risk-premium shocks in the U.S. economy during the Great Recession. Specifically, Kulish, Morley and Robinson (2017) estimate the Smets and Wouters (2007) model for the sample period of 1983Q1-2014Q2, which includes the period where the ZLB was effectively binding in the U.S. economy. These shocks are found to be largely responsible for the large negative output gap from 2009 up to the end of the sample in 2014Q2 (see Appendix E of their paper) ${ }^{16}$

Figure 8 plots the impulse responses based on the assumed scenario above for two alternative inflation target policies. ${ }^{17}$ In the first policy, the central bank is assumed to keep its current inflation target of $2 \%$ per annum (dashed line), whereas the target is instead raised from $2 \%$ to $4 \%$ at quarter 1 under the second policy (solid line). To account for the ZLB constraint, we solve the model under each policy using the OccBin toolkit described in Guerrieri and Iacoviello (2015). The figure also includes a notional case where the target is kept at $2 \%$ and the ZLB constraint were not imposed (dash-dotted line). In all cases, we assume that the economy is initially at quarter 0 with $2 \%$ per annum inflation and inflation target, $2.5 \%$ per annum nominal interest rate, $0.5 \%$ per annum real interest rate, zero output gap, and expected inflation coinciding with its target. This starting point is consistent with the recent estimate of the natural rate of interest for the U.S. economy as suggested by Holston, Laubach and Williams (2017) and Del Negro et al. (2019), among others.

As shown in Figure 8, with a constant inflation target, the contractionary risk-premium shocks cause the nominal (policy) rate to fall significantly and eventually lead to a binding

\footnotetext{
${ }^{16}$ Furlanetto and Groshenny (2016) estimate a medium-scale model with search and matching frictions in the labor market in addition to sticky prices and wages and find that the rise in the unemployment rate during the Great Recession is mainly attributed to a series of negative demand shocks including risk-premium shocks.

${ }^{17}$ Irrespective of the inflation target policy, the monetary authority still conducts an interest-rate feedback policy according to the Taylor-type rule in (13).
} 
Figure 8: Smets and Wouters model: Raising the inflation target under large contractionary shocks with the ZLB
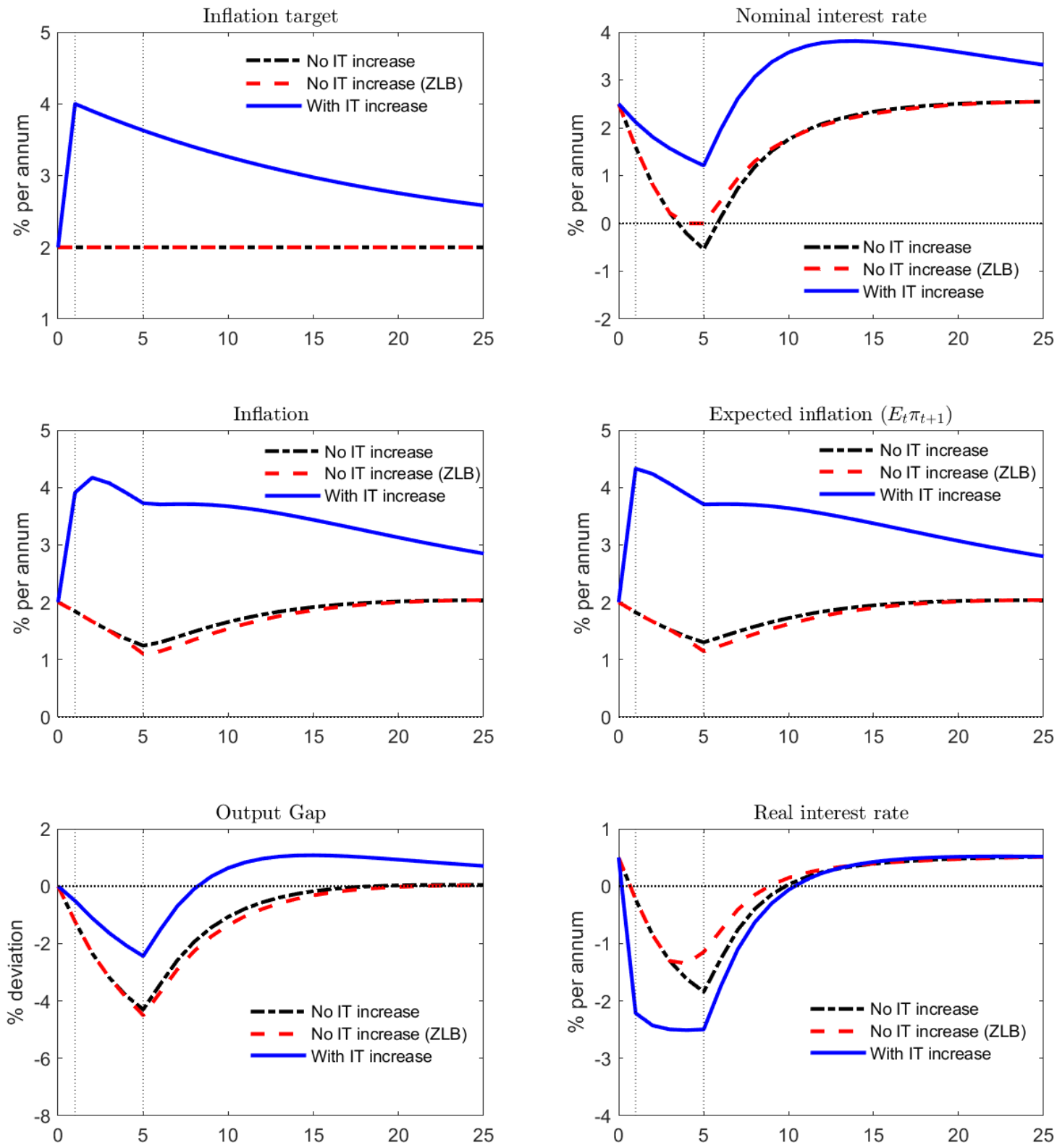

Note: This figure compares the impulse responses of selective variables to a series of large contractionary shocks in which the monetary authority (i) raises its inflation target from $2 \%$ to $4 \%$ per annum at quarter 1 (solid line), and (ii) keeps the $2 \%$ target, with (dashed line) and without (dash-dotted line) the zero lower bound constraint on the nominal interest rate. The contractionary shocks are given by four standard deviation risk-premium shocks of five consecutive quarters at quarters 1-5. We assume $\phi_{\pi^{*}}=0.95$, while all other parameters are set to the posterior mode estimates in Smets and Wouters (2007) for the sample period of 1984Q1-2004Q4. The economy is initially at quarter 0 with $2 \%$ inflation target and inflation per annum, $2.5 \%$ nominal interest rate per annum, $0.5 \%$ real interest rate per annum, and $0 \%$ output gap. 
ZLB at quarters 4-5. Both inflation and expected inflation fall to roughly $1 \%$ per annum after five quarters. The real interest rate declines in the first several quarters as the nominal rates decrease by more than expected inflation. In fact, the real rates are negative and do not turn positive until quarter 9 . The increase in the risk premium leads to output contractions initially, with the output gap reaching $-4 \%$ at its trough in quarter 5. Starting in quarter 6 , the ZLB constraint is no longer binding and the nominal rate slowly rises again, as do inflation and the output gap. The effect of the shocks on the economy appears to completely dissipate after 25 quarters. Comparing the responses to the notional responses in which the ZLB constraint were not imposed, the differences are quantitatively minor. In the latter, despite the large contractionary shocks, the notional policy rate turns negative only for two periods in quarters $4-5$, with a trough of $-0.54 \%$.

When the inflation target is raised instead in conjunction with the contractionary riskpremium shocks, the nominal rates do decrease in the first five quarters. But the rate is never in danger of reaching its $0 \%$ lower bound and is only as low as $1.2 \%$ in quarter 5 . This stark contrast to the first policy is a direct consequence of the monetary authority needing to increase the nominal rate in order to raise the inflation target, as previously shown in Figure 6-or put another way, the marginal effect of raising the inflation target on the nominal rate relative to no target increase is positive. Under this alternative policy, even with the presence of large contractionary risk-premium shocks inflation increases in the first two quarters. Expected inflation increases in quarter 1 by more than the increase in the inflation target, highlighting the forward-looking dynamics of the price-setting mechanism in the model. This leads to a much larger decline in the real rates and to less negative output gaps. In fact, the output gaps are positive starting from quarter 9.

The result in Figure 8 shows that raising the inflation target could be an effective tool to mitigate the output loss and the cost of potentially hitting the ZLB on the nominal rate amidst the prospect of large contractionary shocks when the natural rates of interest are already low. Relative to keeping the inflation target at $2 \%$ with a ZLB constraint (dashed lines), we find that over 25 quarters, raising the inflation target to $4 \%$ at quarter 0 would result in a cumulative gain of output of $35.6 \% .^{18}$ This substantial output gain and the fact

\footnotetext{
${ }^{18}$ Kulish, Morley and Robinson (2017) take the same approach to calculate the loss of output relative to
} 
that the ZLB constraint on the nominal interest rate is less likely to bind over time make raising the inflation target an appealing policy option.

More persistent, but smaller risk-premium shocks To generate a binding ZLB constraint in Figure 8 we rely on a series of fairly large (4-standard deviation) risk-premium shocks. Even then, the ZLB only binds for two quarters and the associated cost of the constraint is relatively minor: relative to the notional case of no ZLB constraint (dash-dotted line), the cumulative output loss over 25 quarters is only $3.4 \%$. One main reason for this result is that the estimated persistence of the risk-premium shock in Smets and Wouters (2007) is quite low, with the posterior mode of the $\operatorname{AR}(1)$ parameter $\rho_{b}$ equal to 0.14 for the sample period of 1984Q1-2004Q4. Kulish, Morley and Robinson (2017), however, find a much higher estimate of $\rho_{b}=0.95$ when including the post-2009 period. This implies the ZLB constraint could now be binding for smaller contractionary shocks, increasing the possibility and the cost of hitting the ZLB. We investigate this scenario by reproducing the experiment in Figure 8 but with $\rho_{b}=0.5$, depicted in Figure 9. Here, we assume that from quarters 1-5, the economy is hit by a series of 2-standard deviation contractionary risk-premium shocks. All other parameter values and assumptions are identical as previously.

Under these more persistent but smaller risk-premium shocks, the ZLB on the nominal rate is now binding for four periods from quarters 3-6 when the inflation target is kept at 2\% (dashed line). Inflation and expected inflation decline by more compared to their responses in Figure 8. The output gap turns more negative and is now $-6.5 \%$ at its trough in quarter 5. Despite the smaller shock, the cost of binding ZLB constraint is markedly higher when the shocks are more persistent. In the notional case of no ZLB constraint (dash-dotted line), the monetary authority would set negative policy rates from quarters 3-8, resulting in higher inflation expectations and more negative real rates. Relative to the case with a ZLB constraint, the cumulative loss of output over 25 quarters would have been $15 \%$ lower if the monetary authority were able to set negative nominal interest rates.

Raising the inflation target would further mitigate the output loss. Under this policy (solid line), output would be cumulatively higher by $47 \%$ relative to the constant inflation the counterfactual. 
Figure 9: Smets and Wouters model: Raising the inflation target under large contractionary shocks with the ZLB - a higher shock persistence
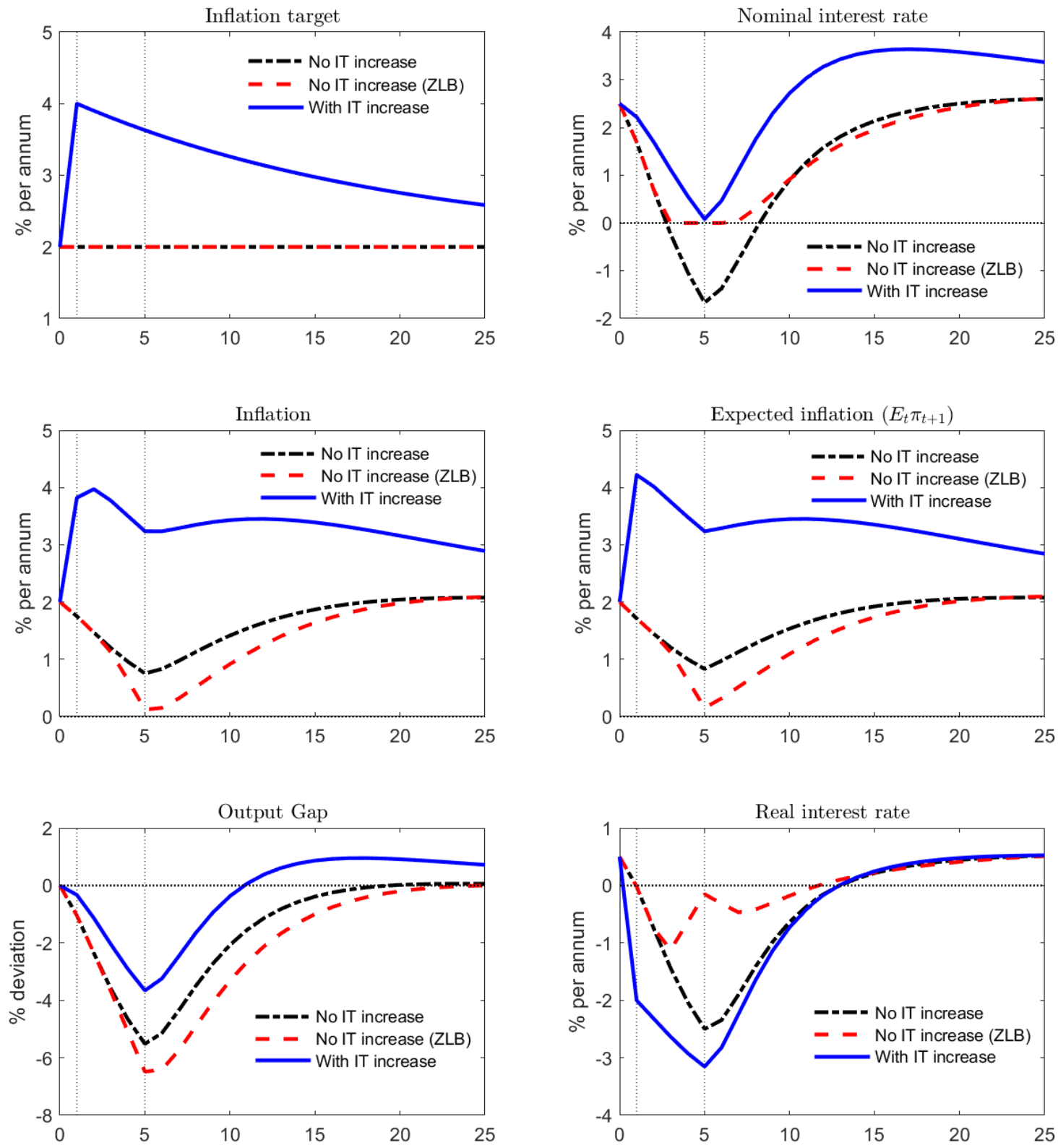

Note: This figure reproduces Figure 8, but under $\rho_{b}=0.50$ (higher persistence of the risk-premium shock) instead of the benchmark $\rho_{b}=0.14$. The contractionary shocks are now given by two standard deviation risk-premium shocks of five consecutive quarters at quarters 1-5. All other parameter values and assumptions are as in Figure 8.

target policy (dashed line). The driver for this output gain is the increase in expected inflation, leading to more negative real rates. The ZLB constraint on the nominal interest 
rate never binds, owing to the Neo-Fisherian property in the model. A highly persistent contractionary shock process thus makes raising the inflation target more appealing.

\section{Conclusion}

Would raising the inflation target require an increase in the nominal interest rate in the short run? We answer this important policy question, first analytically in a small-scale New Keynesian model with backward-looking components where a closed-form solution is available, and then in a medium-scale model in Smets and Wouters (2007) calibrated to the U.S. economy.

We find that the short-run comovement between inflation and the nominal interest rate conditional on changes in the inflation target is more likely to be positive, all else equal, as the monetary authority reacts less aggressively to the deviation of inflation from its target. Meanwhile, features of the model that enhance backward-looking behavior, such as backward price indexation and habit formation in consumption, are shown to reduce the likelihood of the positive comovement. However, our investigations reveal that this positive comovement or Neo-Fisherism occurs across a wide range of empirically-plausible parameter values.

The Neo-Fisherian property is also shown to be prevalent in the Smets and Wouters (2007) model for various alternative parameterizations of the model. This result is robust to the imposition of the zero lower bound constraint on the nominal interest rate. Our finding thus indicates that the U.S. Federal Reserve would likely need to raise the federal funds rate in the short run should it choose to raise the $2 \%$ inflation target. Using the Smets and Wouters model, we also show that raising the inflation target could be an effective alternative policy framework to reduce the possibility of a binding zero lower bound constraint on the nominal interest rate and to mitigate the potentially large output loss. 


\section{References}

Ball, Laurence. 2014. "The Case for a Long-Run Inflation Target of Four Percent." International Monetary Fund Working Paper 1492.

Bernanke, Ben, Mark Gertler, Simon Gilchrist, John B Taylor, and Michael Woodford. 1999. "Handbook of macroeconomics." The financial accelerator in a quantitative business cycle framework. Elsevier, 1341-1393.

Bernanke, Ben S. 2017. "Monetary policy in a new era." Peterson Institute.

Bhattarai, Saroj, Jae Won Lee, and Woong Yong Park. 2014a. "Inflation dynamics: The role of public debt and policy regimes." Journal of Monetary Economics, 67: 93-108.

Bhattarai, Saroj, Jae Won Lee, and Woong Yong Park. 2014b. "Price indexation, habit formation, and the Generalized Taylor Principle." Journal of Economic Dynamics and Control, 48: 218-225.

Bhattarai, Saroj, Jae Won Lee, and Woong Yong Park. 2016. "Policy regimes, policy shifts, and US business cycles." Review of Economics and Statistics, 98(5): 968-983.

Bilbiie, Florin Ovidiu. 2018. "Neo-Fisherian Policies and Liquidity Traps."

Blanchard, Olivier. 2016. "Where to from Here? The Phillips Curve: Back to the 60s?" The American Economic Review, 106(5): 31-34.

Blanchard, Olivier, Giovanni Dell'Ariccia, and Paolo Mauro. 2010. "Rethinking macroeconomic policy." Journal of Money, Credit and Banking, 42: 199-215.

Bullard, James, and Kaushik Mitra. 2002. "Learning about monetary policy rules." Journal of Monetary Economics, 49(6): 1105-1129.

Calvo, Guillermo A. 1983. "Staggered prices in a utility-maximizing framework." Journal of Monetary Economics, 12(3): 383-398.

Castelnuovo, Efrem. 2012. "Testing the Structural Interpretation of the Price Puzzle with a Cost-Channel Model." Oxford Bulletin of Economics and Statistics, 74(3): 425-452. 
Christiano, Lawrence J, Martin Eichenbaum, and Charles L Evans. 2005. "Nominal rigidities and the dynamic effects of a shock to monetary policy." Journal of Political Economy, 113(1): 1-45.

Cochrane, John H. 2016. "Do Higher Interest Rates Raise or Lower Inflation?" Working paper, February.

Cogley, Timothy, Giorgio E Primiceri, and Thomas J Sargent. 2010. "Inflation-gap persistence in the US." American Economic Journal: Macroeconomics, 2(1): 43-69.

De Michelis, Andrea, and Matteo Iacoviello. 2016. "Raising an inflation target: The Japanese experience with Abenomics." European Economic Review, 88: 67-87.

Del Negro, Marco, Domenico Giannone, Marc P Giannoni, and Andrea Tambalotti. 2019. "Global trends in interest rates." Journal of International Economics, 118: 248-262.

Del Negro, Marco, Marc P Giannoni, and Frank Schorfheide. 2015. "Inflation in the Great Recession and New Keynesian models." American Economic Journal: Macroeconomics, $7(1): 168-96$.

Eo, Yunjong, and Denny Lie. 2019. "The role of inflation target adjustment in stabilization policy." Journal of Money, Credit and Banking, in press.

Eo, Yunjong, and Denny Lie. 2020. "Average inflation targeting and interest-rate smoothing." Economics Letters, 189: 109005.

Fève, Patrick, Julien Matheron, and Jean-Guillaume Sahuc. 2010. "Inflation target shocks and monetary policy inertia in the euro area." The Economic Journal, 120(547): 11001124.

Frankel, Jeffrey. 2013. "Nominal-GDP targets, without losing the inflation anchor." Is Inflation Targeting Dead?, 90.

Furlanetto, Francesco, and Nicolas Groshenny. 2016. "Mismatch shocks and unemployment during the Great Recession." Journal of Applied Econometrics, 31(7): 1197-1214. 
Galí, Jordi. 2015. Monetary policy, inflation, and the business cycle: an introduction to the new Keynesian framework and its applications. Princeton University Press.

Galı, Jordi, and Mark Gertler. 1999. "Inflation dynamics: A structural econometric analysis." Journal of Monetary Economics, 44(2): 195-222.

Garín, Julio, Robert Lester, and Eric Sims. 2018. "Raise Rates to Raise Inflation? NeoFisherianism in the New Keynesian Model." Journal of Money, Credit and Banking, 50.

Gaspar, Vitor, Frank Smets, and David Vestin. 2010. "Is the time ripe for price-level path stability?" Challenges in Central Banking: The Current Institutional Environment and Forces Affecting Monetary Policy, 21-51.

Guerrieri, Luca, and Matteo Iacoviello. 2015. "OccBin: A toolkit for solving dynamic models with occasionally binding constraints easily." Journal of Monetary Economics, 70: 22-38.

Hall, Robert E. 1988. "Intertemporal substitution in consumption." Journal of political economy, 96(2): 339-357.

Holston, Kathryn, Thomas Laubach, and John C Williams. 2017. "Measuring the natural rate of interest: International trends and determinants." Journal of International Economics, 108: S59-S75.

Ireland, Peter N. 2007. "Changes in the Federal Reserve's inflation target: Causes and consequences." Journal of Money, Credit and Banking, 39(8): 1851-1882.

Kiley, Michael T, and John M Roberts. 2017. "Monetary policy in a low interest rate world." Brookings Papers on Economic Activity, 2017(1): 317-396.

Krugman, Paul. 2014. "Inflation targets reconsidered." Navigating Monetary Policy in the New Normal 8, 110.

Kulish, Mariano, James Morley, and Tim Robinson. 2017. "Estimating DSGE models with zero interest rate policy." Journal of Monetary Economics, 88: 35-49.

Kuttner, Ken, and Tim Robinson. 2010. "Understanding the flattening Phillips curve." The North American Journal of Economics and Finance, 21(2): 110-125. 
Kydland, Finn E, and Edward C Prescott. 1982. "Time to build and aggregate fluctuations." Econometrica: Journal of the Econometric Society, 1345-1370.

McCallum, Bennett T, and Edward Nelson. 1999. "Nominal income targeting in an openeconomy optimizing model." Journal of Monetary economics, 43(3): 553-578.

Nessén, Marianne, and David Vestin. 2005. "Average inflation targeting." Journal of Money, Credit and Banking, 837-863.

Roberts, John M. 2006. "Monetary Policy and Inflation Dynamics." International Journal of Central Banking, 2(3).

Rosengren, Eric S. 2018. "Reviewing monetary policy frameworks: remarks at a Forum on the Federal Reserve's Inflation Target." In the Hutchins Center on Fiscal and Monetary Policy, the Brookings Institution, Washington, DC.

Schmitt-Grohé, Stephanie, and Martín Uribe. 2014. "Liquidity Traps: an Interest-rate-based Exit Strategy." The Manchester School, 82(S1): 1-14.

Schmitt-Grohé, Stephanie, and Martín Uribe. 2017. "Liquidity traps and jobless recoveries." American Economic Journal: Macroeconomics, 9(1): 165-204.

Smets, Frank, and Rafael Wouters. 2007. "Shocks and frictions in US business cycles: A Bayesian DSGE approach." The American Economic Review, 97(3): 586-606.

Summers, Lawrence H, David Wessel, and John David Murray. 2018. "Rethinking the Fed's 2 percent inflation target." In A report from the Hutchins Center on Fiscal $\mathscr{E}$ Monetary Policy at Brookings. Hutchings Center on Fiscal \& Monetary Policy.

Svensson, Lars EO. 2019. "Monetary policy strategies for the Federal Reserve." Prepared for the Cconference Monetary policy strategy, tools and communicafion pracfices-A Fed listens event, Federal Reserve Bak of Chicago.

Taylor, John B. 1993. "Discretion versus policy rules in practice." Carnegie-Rochester Conference Series on Public Policy, 39: 195-214. 
Williams, John C. 2016. "Monetary Policy in a Low R-star World." FRBSF Economic Letter, 23.

Williams, John C. 2017. "Preparing for the Next Storm: Reassessing Frameworks and Strategies in a Low R-star World." FRBSF Economic Letter, 13.

Williamson, Stephen. 2016. "Neo-Fisherism: A Radical Idea, or the Most Obvious Solution to the Low-Inflation Problem?" The Regional Economist, FRBSL.

Yun, Tack. 1996. "Nominal price rigidity, money supply endogeneity, and business cycles." Journal of Monetary Economics, 37(2): 345-370. 


\section{Appendices}

\section{A Proofs}

Lemma 1 The solution for $i_{t}$ to the New Keynesian Model with the IS curve (8), the hybrid NKPC (2), and the Taylor-type rule (5) is given by

$$
i_{t}=\Gamma_{0} \pi_{t}^{*}+\Gamma_{1} \pi_{t-1}
$$

where

$$
\begin{aligned}
& \Gamma_{0}=\frac{1}{\lambda_{2}-\phi_{\pi^{*}}} \frac{1}{\lambda_{3}-\phi_{\pi^{*}}} \frac{\psi_{\pi} \kappa \sigma^{-1}}{\beta} \times \\
& \left\{\phi_{\pi^{*}}-\frac{\left(1-\phi_{\pi^{*}}\right)\left(1-\beta \phi_{\pi^{*}}\right)}{\kappa \sigma^{-1}}-\frac{\tau}{\kappa \sigma^{-1}}\left\{1+\beta\left(1-\phi_{\pi^{*}}\right)\right\}+\frac{\tau}{\kappa \sigma^{-1}}\left(\frac{\lambda_{2}+\lambda_{3}-\phi_{\pi^{*}}}{\lambda_{2} \lambda_{3}}\right)\right\}, \\
& \Gamma_{1}=\lambda_{1} \psi_{\pi},
\end{aligned}
$$

and $\lambda_{1}, \lambda_{2}$, and $\lambda_{3}$ are eigenvalues associated with the model solution such that

$$
\begin{aligned}
\left|\lambda_{1}\right|<1 & <\left|\lambda_{2}\right| \leq\left|\lambda_{3}\right| \\
\lambda_{1} \lambda_{2}+\lambda_{2} \lambda_{3}+\lambda_{3} \lambda_{1} & =\frac{1+\gamma_{b}+\tilde{\kappa} \sigma^{-1} \psi_{\pi}}{\gamma_{f}}>0, \\
\lambda_{1} \lambda_{2} \lambda_{3} & =\frac{\gamma_{b}}{\gamma_{f}}>0 \\
\lambda_{1}+\lambda_{2}+\lambda_{3} & =\frac{1+\gamma_{f}+\tilde{\kappa} \sigma^{-1}}{\gamma_{f}}>0 ; \\
\gamma_{f}=\frac{\beta}{1+\beta \tau}, & \gamma_{b}=\frac{\tau}{1+\beta \tau}, \quad \tilde{\kappa}=\frac{\kappa}{1+\beta \tau} .
\end{aligned}
$$

Proof. The model is given by

$$
\begin{aligned}
y_{t} & =E_{t} y_{t+1}-\sigma^{-1}\left(i_{t}-E_{t} \pi_{t+1}\right) \\
\pi_{t} & =\gamma_{f} E_{t} \pi_{t+1}+\gamma_{b} \pi_{t-1}+\tilde{\kappa} y_{t}, \\
i_{t} & =\psi_{\pi}\left(\pi_{t}-\pi_{t}^{*}\right) .
\end{aligned}
$$


We want to collapse the three equations in the model above into a single equation for $i_{t}$. Push (A.4) one period ahead and take expectations of it in time t (i.e., $E_{t}$ ) as

$$
E_{t} i_{t+1}=\psi_{\pi} E_{t}\left(\pi_{t+1}-\pi_{t+1}^{*}\right)
$$

Then substitute (A.5) into the IS curve (A.2) to remove $E_{t} \pi_{t+1}$ as

$$
y_{t}=E_{t} y_{t+1}-\sigma^{-1} E_{t}\left(i_{t}-\frac{1}{\psi_{\pi}} i_{t+1}-\pi_{t+1}^{*}\right) .
$$

Use a lag operator L as $E_{t} x_{t+1}=E_{t} L^{-1} x_{t}$ for a variable $x_{t}$, (A.3) and (A.6) are expressed as

$$
E_{t}\left(1-\gamma_{f} L^{-1}-\gamma_{b} L\right) \pi_{t}=\tilde{\kappa} y_{t}
$$

and

$$
E_{t}\left(1-L^{-1}\right) y_{t}=-\sigma^{-1} E_{t}\left(i_{t}-\frac{1}{\psi_{\pi}} i_{t+1}-\pi_{t+1}^{*}\right) .
$$

Now, substitute (A.4) and (A.8) into (A.7) as

$$
\begin{aligned}
E_{t}\left(1-\gamma_{f} L^{-1}-\gamma_{b} L\right)\left(\frac{1}{\psi_{\pi}} i_{t}+\pi_{t}^{*}\right) & =-E_{t} \tilde{\kappa} \sigma^{-1}\left(1-L^{-1}\right)^{-1}\left(i_{t}-\frac{1}{\psi_{\pi}} i_{t+1}-\pi_{t+1}^{*}\right) \\
& =-E_{t} \tilde{\kappa} \sigma^{-1}\left(1-L^{-1}\right)^{-1}\left(\left(1-\frac{1}{\psi_{\pi}} L^{-1}\right) i_{t}-\pi_{t+1}^{*}\right)
\end{aligned}
$$

Multiply both sides of (A.9) by $\left(1-L^{-1}\right)$ as

$$
E_{t}\left(1-L^{-1}\right)\left(1-\gamma_{f} L^{-1}-\gamma_{b} L\right)\left(\frac{1}{\psi_{\pi}} i_{t}+\pi_{t}^{*}\right)=-\tilde{\kappa} \sigma^{-1} E_{t}\left(\left(1-\frac{1}{\psi_{\pi}} L^{-1}\right) i_{t}-\pi_{t+1}^{*}\right)
$$

Rearrange (A.10) and collect terms related to $i_{t}$ and $\pi_{t}^{*}$, respectively as

$$
\begin{aligned}
& E_{t}\left[\left\{\frac{1+\gamma_{b}-\gamma_{b} L-\left(1+\gamma_{f}\right) L^{-1}+\gamma_{f} L^{-2}}{\psi_{\pi}}+\tilde{\kappa} \sigma^{-1}\left(1-\frac{1}{\psi_{\pi}} L^{-1}\right)\right\} i_{t}\right] \\
= & E_{t}\left[\left\{-1-\gamma_{b}+\gamma_{b} L+\left(1+\gamma_{f}\right) L^{-1}-\gamma_{f} L^{-2}+\tilde{\kappa} \sigma^{-1} L^{-1}\right\} \pi_{t}^{*}\right] .
\end{aligned}
$$


The LHS of (A.11) is given by

$$
\begin{aligned}
& E_{t}\left[\left\{\frac{1+\gamma_{b}-\gamma_{b} L-\left(1+\gamma_{f}\right) L^{-1}+\gamma_{f} L^{-2}}{\psi_{\pi}}+\tilde{\kappa} \sigma^{-1}\left(1-\frac{1}{\psi_{\pi}} L^{-1}\right)\right\} i_{t}\right] \\
= & \frac{1}{\psi_{\pi}} E_{t}\left[\left\{1+\gamma_{b}-\gamma_{b} L-\left(1+\gamma_{f}\right) L^{-1}+\gamma_{f} L^{-2}+\tilde{\kappa} \sigma^{-1} \psi_{\pi}-\tilde{\kappa} \sigma^{-1} L^{-1}\right\} i_{t}\right] \\
= & \frac{1}{\psi_{\pi}} E_{t}\left[\left\{\left(1+\gamma_{b}+\tilde{\kappa} \sigma^{-1} \psi_{\pi}\right)-\gamma_{b} L-\left(1+\gamma_{f}+\tilde{\kappa} \sigma^{-1}\right) L^{-1}+\gamma_{f} L^{-2}\right\} i_{t}\right] \\
= & \frac{\gamma_{f}}{\psi_{\pi}} E_{t}\left[\left\{\frac{1+\gamma_{b}+\tilde{\kappa} \sigma^{-1} \psi_{\pi}}{\gamma_{f}}-\frac{\gamma_{b}}{\gamma_{f}} L-\frac{1+\gamma_{f}+\tilde{\kappa} \sigma^{-1}}{\gamma_{f}} L^{-1}+L^{-2}\right\} i_{t}\right] \\
= & \frac{\gamma_{f}}{\psi_{\pi}} E_{t}\left[\left(1-\lambda_{1} L\right)\left(\lambda_{2}-L^{-1}\right)\left(\lambda_{3}-L^{-1}\right) i_{t}\right] .
\end{aligned}
$$

The last line in (A.12) uses the following lag operator expression

$$
\left(1-\lambda_{1} L\right)\left(\lambda_{2}-L^{-1}\right)\left(\lambda_{3}-L^{-1}\right)=\left(\lambda_{1} \lambda_{2}+\lambda_{2} \lambda_{3}+\lambda_{3} \lambda_{1}\right)-\lambda_{1} \lambda_{2} \lambda_{3} L-\left(\lambda_{1}+\lambda_{2}+\lambda_{3}\right) L^{-1}+L^{-2} .
$$

In short, eigenvalues $\lambda_{1}, \lambda_{2}$, and $\lambda_{3}$ are such that

$$
\begin{aligned}
\lambda_{1} \lambda_{2}+\lambda_{2} \lambda_{3}+\lambda_{3} \lambda_{1} & =\frac{1+\gamma_{b}+\tilde{\kappa} \sigma^{-1} \psi_{\pi}}{\gamma_{f}}>0, \\
\lambda_{1} \lambda_{2} \lambda_{3} & =\frac{\gamma_{b}}{\gamma_{f}}>0, \\
\lambda_{1}+\lambda_{2}+\lambda_{3} & =\frac{1+\gamma_{f}+\tilde{\kappa} \sigma^{-1}}{\gamma_{f}}>0,
\end{aligned}
$$

and

$$
\left|\lambda_{1}\right|<1<\left|\lambda_{2}\right| \leq\left|\lambda_{3}\right|
$$

to ensure determinacy. Also, because $\gamma_{b}, \gamma_{f}, \tilde{\kappa}, \psi_{\pi}$, and $\sigma$ are all positive, $\lambda_{1} \lambda_{2}+\lambda_{2} \lambda_{3}+\lambda_{3} \lambda_{1}>$ $0, \lambda_{1} \lambda_{2} \lambda_{3}>0$, and $\lambda_{1}+\lambda_{2}+\lambda_{3}>0$.

The RHS of (A.11) is given by

$$
\begin{aligned}
& E_{t}\left[\left\{-1-\gamma_{b}+\gamma_{b} L+\left(1+\gamma_{f}\right) L^{-1}-\gamma_{f} L^{-2}+\tilde{\kappa} \sigma^{-1} L^{-1}\right\} \pi_{t}^{*}\right] \\
= & E_{t}\left[\left\{\left(-1-\gamma_{b}\right)+\left(1+\gamma_{f}+\tilde{\kappa} \sigma^{-1}\right) L^{-1}-\gamma_{f} L^{-2}\right\} \pi_{t}^{*}\right]+\gamma_{b} \pi_{t-1}^{*} \\
= & \left\{\left(-1-\gamma_{b}\right)+\left(1+\gamma_{f}+\tilde{\kappa} \sigma^{-1}\right) \phi_{\pi^{*}}-\gamma_{f} \phi_{\pi^{*}}^{2}\right\} \pi_{t}^{*}+\gamma_{b} \pi_{t-1}^{*}
\end{aligned}
$$


because $E_{t} \pi_{t+1}^{*}=E_{t} L^{-1} \pi_{t}^{*}=\phi_{\pi^{*}} \pi_{t}^{*}$.

Combine (A.12) for the LHS of (A.11) and (A.18) for the RHS of (A.11) as

$$
\begin{aligned}
& \frac{\gamma_{f}}{\psi_{\pi}} E_{t}\left[\left(1-\lambda_{1} L\right)\left(\lambda_{2}-L^{-1}\right)\left(\lambda_{3}-L^{-1}\right) i_{t}\right] \\
= & \left\{\left(-1-\gamma_{b}\right)+\left(1+\gamma_{f}+\tilde{\kappa} \sigma^{-1}\right) \phi_{\pi^{*}}-\gamma_{f} \phi_{\pi^{*}}^{2}\right\} \pi_{t}^{*}+\gamma_{b} \pi_{t-1}^{*} .
\end{aligned}
$$

Multiply both sides of (A.19) by $\left(\lambda_{2}-L^{-1}\right)^{-1}\left(\lambda_{3}-L^{-1}\right)^{-1}$ as

$$
\begin{aligned}
& \frac{\gamma_{f}}{\psi_{\pi}} E_{t}\left[\left(1-\lambda_{1} L\right) i_{t}\right] \\
= & E_{t}\left[\left(\lambda_{2}-L^{-1}\right)^{-1}\left(\lambda_{3}-L^{-1}\right)^{-1}\left\{\left(-1-\gamma_{b}\right)+\left(1+\gamma_{f}+\tilde{\kappa} \sigma^{-1}\right) \phi_{\pi^{*}}-\gamma_{f} \phi_{\pi^{*}}^{2}\right\} \pi_{t}^{*}\right] \\
& +E_{t}\left[\left(\lambda_{2}-L^{-1}\right)^{-1}\left(\lambda_{3}-L^{-1}\right)^{-1} \gamma_{b} \pi_{t-1}^{*}\right] .
\end{aligned}
$$

The RHS of (A.20) can be rearranged as

$$
\begin{aligned}
& E_{t}\left[\left(\lambda_{2}-L^{-1}\right)^{-1}\left(\lambda_{3}-L^{-1}\right)^{-1}\left\{\left(-1-\gamma_{b}\right)+\left(1+\gamma_{f}+\tilde{\kappa} \sigma^{-1}\right) \phi_{\pi^{*}}-\gamma_{f} \phi_{\pi^{*}}^{2}\right\} \pi_{t}^{*}\right] \\
& +E_{t}\left[\left(\lambda_{2}-L^{-1}\right)^{-1}\left(\lambda_{3}-L^{-1}\right)^{-1} \gamma_{b} \pi_{t-1}^{*}\right] \\
= & E_{t}\left[\left(\lambda_{3}-L^{-1}\right)^{-1} \frac{1}{\lambda_{2}-\phi_{\pi^{*}}}\left\{\left(-1-\gamma_{b}\right)+\left(1+\gamma_{f}+\tilde{\kappa} \sigma^{-1}\right) \phi_{\pi^{*}}-\gamma_{f} \phi_{\pi^{*}}^{2}+\frac{\gamma_{b}}{\lambda_{2}}\right\} \pi_{t}^{*}\right] \\
& +E_{t}\left[\left(\lambda_{3}-L^{-1}\right)^{-1} \frac{1}{\lambda_{2}} \gamma_{b} \pi_{t-1}^{*}\right] \\
= & \frac{1}{\lambda_{2}-\phi_{\pi^{*}}} \frac{1}{\lambda_{3}-\phi_{\pi^{*}}}\left\{\left(-1-\gamma_{b}\right)+\left(1+\gamma_{f}+\tilde{\kappa} \sigma^{-1}\right) \phi_{\pi^{*}}-\gamma_{f} \phi_{\pi^{*}}^{2}+\frac{\gamma_{b}}{\lambda_{2}}+\frac{\gamma_{b}}{\lambda_{3}}-\frac{\phi_{\pi^{*}} \gamma_{b}}{\lambda_{2} \lambda_{3}}\right\} \pi_{t}^{*} \\
& +\frac{1}{\lambda_{2}} \frac{1}{\lambda_{3}} \gamma_{b} \pi_{t-1}^{*}
\end{aligned}
$$

because

$$
\begin{aligned}
E_{t}\left(\lambda_{2}-L^{-1}\right)^{-1} \pi_{t}^{*} & =E_{t} \frac{1}{\lambda_{2}}\left(1+\frac{1}{\lambda_{2}} L^{-1}+\frac{1}{\lambda_{2}^{2}} L^{-2}+\cdots\right) \pi_{t}^{*} \\
& =E_{t} \frac{1}{\lambda_{2}}\left(\pi_{t}^{*}+\frac{1}{\lambda_{2}} \pi_{t+1}^{*}+\frac{1}{\lambda_{2}^{2}} \pi_{t+2}^{*}+\cdots\right)=\frac{1}{\lambda_{2}}\left(\pi_{t}^{*}+\frac{\phi_{\pi^{*}}}{\lambda_{2}} \pi_{t}^{*}+\frac{\phi_{\pi^{*}}^{2}}{\lambda_{2}^{2}} \pi_{t}^{*}+\cdots\right) \\
& =\frac{1}{\lambda_{2}} \frac{1}{1-\phi_{\pi^{*}} / \lambda_{2}} \pi_{t}^{*}=\frac{1}{\lambda_{2}-\phi_{\pi^{*}}} \pi_{t}^{*}
\end{aligned}
$$


and similarly

$$
E_{t}\left(\lambda_{2}-L^{-1}\right)^{-1} \pi_{t-1}^{*}=E_{t} \frac{1}{\lambda_{2}}\left(1+\frac{1}{\lambda_{2}} L^{-1}+\frac{1}{\lambda_{2}^{2}} L^{-2}+\cdots\right) \pi_{t-1}^{*}=\frac{1}{\lambda_{2}} \pi_{t-1}^{*}+\frac{1}{\lambda_{2}} \frac{1}{\lambda_{2}-\phi_{\pi^{*}}} \pi_{t}^{*}
$$

The derivations above also apply to expanding for $\left(\lambda_{3}-L^{-1}\right)^{-1}$. Note that (A.17) ensures $\left|\phi_{\pi^{*}} / \lambda_{2}\right|<1$ and $\left|\phi_{\pi^{*}} / \lambda_{3}\right|<1$.

Finally, the solution is given by

$$
\begin{aligned}
& i_{t}-\lambda_{1} i_{t-1} \\
= & \frac{\psi_{\pi}}{\gamma_{f}} \frac{1}{\lambda_{2}-\phi_{\pi^{*}}} \frac{1}{\lambda_{3}-\phi_{\pi^{*}}}\left\{\left(-1-\gamma_{b}\right)+\left(1+\gamma_{f}+\tilde{\kappa} \sigma^{-1}\right) \phi_{\pi^{*}}-\gamma_{f} \phi_{\pi^{*}}^{2}+\frac{\gamma_{b}}{\lambda_{2}}+\frac{\gamma_{b}}{\lambda_{3}}-\frac{\phi_{\pi^{*}} \gamma_{b}}{\lambda_{2} \lambda_{3}}\right\} \pi_{t}^{*} \\
& +\frac{\psi_{\pi}}{\gamma_{f}} \frac{1}{\lambda_{2}} \frac{1}{\lambda_{3}} \gamma_{b} \pi_{t-1}^{*} \\
= & \frac{1}{\lambda_{2}-\phi_{\pi^{*}}} \frac{1}{\lambda_{3}-\phi_{\pi^{*}}} \frac{\psi_{\pi}}{\beta}\left\{\kappa \sigma^{-1} \phi_{\pi^{*}}-\left(1-\phi_{\pi^{*}}\right)\left(1+\beta \tau-\beta \phi_{\pi^{*}}\right)\right. \\
& \left.+\tau\left(\frac{\lambda_{2}+\lambda_{3}-\phi_{\pi^{*}}}{\lambda_{2} \lambda_{3}}-1\right)\right\} \pi_{t}^{*}+\frac{1}{\lambda_{2}} \frac{1}{\lambda_{3}} \frac{\psi_{\pi} \tau}{\beta} \pi_{t-1}^{*} .
\end{aligned}
$$

Substitute $i_{t-1}=\psi_{\pi}\left(\pi_{t-1}-\pi_{t-1}^{*}\right)$ into (A.22) and rearrange it as

$$
\begin{aligned}
i_{t}= & \lambda_{1} \psi_{\pi}\left(\pi_{t-1}-\pi_{t-1}^{*}\right)+\frac{1}{\lambda_{2}-\phi_{\pi^{*}}} \frac{1}{\lambda_{3}-\phi_{\pi^{*}}} \frac{\psi_{\pi} \kappa \sigma^{-1}}{\beta} \times \\
& \left\{\phi_{\pi^{*}}-\frac{\left(1-\phi_{\pi^{*}}\right)\left(1-\beta \phi_{\pi^{*}}\right)+\left\{1+\beta\left(1-\phi_{\pi^{*}}\right)\right\} \tau}{\kappa \sigma^{-1}}+\frac{\tau}{\kappa \sigma^{-1}}\left(\frac{\lambda_{2}+\lambda_{3}-\phi_{\pi^{*}}}{\lambda_{2} \lambda_{3}}\right)\right\} \pi_{t}^{*} \\
+ & \frac{1}{\lambda_{2}} \frac{1}{\lambda_{3}} \frac{\psi_{\pi} \tau}{\beta} \pi_{t-1}^{*} \\
= & \lambda_{1} \psi_{\pi} \pi_{t-1}+\frac{1}{\lambda_{2}-\phi_{\pi^{*}}} \frac{1}{\lambda_{3}-\phi_{\pi^{*}}} \frac{\psi_{\pi} \kappa \sigma^{-1}}{\beta} \times \\
& \left\{\phi_{\pi^{*}}-\frac{\left(1-\phi_{\pi^{*}}\right)\left(1-\beta \phi_{\pi^{*}}\right)+\left\{1+\beta\left(1-\phi_{\pi^{*}}\right)\right\} \tau}{\kappa \sigma^{-1}}+\frac{\tau}{\kappa \sigma^{-1}}\left(\frac{\lambda_{2}+\lambda_{3}-\phi_{\pi^{*}}}{\lambda_{2} \lambda_{3}}\right)\right\} \pi_{t}^{*}
\end{aligned}
$$

because $\lambda_{1} \psi_{\pi}=\frac{1}{\lambda_{2}} \frac{1}{\lambda_{3}} \frac{\psi_{\pi} \tau}{\beta}$ for $\pi_{t-1}^{*}$ from (A.15).

Thus, we show that the solution for $i_{t}$ is expressed as

$$
i_{t}=\Gamma_{0} \pi_{t}^{*}+\Gamma_{1} \pi_{t-1}
$$


where

$$
\begin{aligned}
\Gamma_{0}= & \frac{1}{\lambda_{2}-\phi_{\pi^{*}}} \frac{1}{\lambda_{3}-\phi_{\pi^{*}}} \frac{\psi_{\pi} \kappa \sigma^{-1}}{\beta} \times \\
& \left\{\phi_{\pi^{*}}-\frac{\left(1-\phi_{\pi^{*}}\right)\left(1-\beta \phi_{\pi^{*}}\right)+\left\{1+\beta\left(1-\phi_{\pi^{*}}\right)\right\} \tau}{\kappa \sigma^{-1}}+\frac{\tau}{\kappa \sigma^{-1}}\left(\frac{\lambda_{2}+\lambda_{3}-\phi_{\pi^{*}}}{\lambda_{2} \lambda_{3}}\right)\right\} \\
\Gamma_{1}= & \lambda_{1} \psi_{\pi} .
\end{aligned}
$$

Lemma 2 The solution for $\pi_{t}$ to the New Keynesian Model with the IS curve (A.2), the NKPC (A.3), and the Taylor-type rule (A.4) is given by

$$
\pi_{t}=\Phi_{0} \pi_{t}^{*}+\Phi_{1} \pi_{t-1}
$$

where

$$
\begin{aligned}
\Phi_{0} & =\frac{1}{\left(\lambda_{2}-\phi_{\pi^{*}}\right)\left(\lambda_{3}-\phi_{\pi^{*}}\right)} \frac{\psi_{\pi} \kappa \sigma^{-1}}{\beta} \\
\Phi_{1} & =\lambda_{1}
\end{aligned}
$$

and $\lambda_{1}, \lambda_{2}$, and $\lambda_{3}$ are eigenvalues associated with the model solution in Lemma 1.

Proof. We find the solution for $\pi_{t}$ using a similar approach in Lemma 1. Substitute (A.3) into the IS curve (A.2) to remove $i_{t}$ as

$$
y_{t}=E_{t} y_{t+1}-\sigma^{-1} E_{t}\left(\psi_{\pi}\left(\pi_{t}-\pi_{t}^{*}\right)-\pi_{t+1}\right) .
$$

Use a lag operator as

$$
E_{t}\left(1-L^{-1}\right) y_{t}=E_{t}\left(-\sigma^{-1} \psi_{\pi}+\sigma^{-1} L^{-1}\right) \pi_{t}+\sigma^{-1} \psi_{\pi} \pi_{t}^{*}
$$


Then, we use a lag operator for the hybrid NKPC and substitute (A.30) into it as

$$
\begin{aligned}
E_{t}\left(1-\gamma_{f} L^{-1}-\gamma_{b} L\right) \pi_{t} & =\tilde{\kappa} y_{t}+\mu \pi_{t}^{*} \\
& =\tilde{\kappa} E_{t}\left[\left(1-L^{-1}\right)^{-1}\left(-\sigma^{-1} \psi_{\pi}+\sigma^{-1} L^{-1}\right) \pi_{t}+\left(1-L^{-1}\right)^{-1} \sigma^{-1} \psi_{\pi} \pi_{t}^{*}\right]
\end{aligned}
$$

Rearrange (A.31) and collect terms related to $\pi_{t}$ and $\pi_{t}^{*}$, respectively as

$E_{t}\left[\left(1-\gamma_{f} L^{-1}-\gamma_{b} L\right)-\tilde{\kappa}\left(1-L^{-1}\right)^{-1}\left(-\sigma^{-1} \psi_{\pi}+\sigma^{-1} L^{-1}\right)\right] \pi_{t}=E_{t}\left[\tilde{\kappa}\left(1-L^{-1}\right)^{-1} \sigma^{-1} \psi_{\pi}\right] \pi_{t}^{*}$

Multiply both sides of $(\mathrm{A} .32)$ by $\left(1-L^{-1}\right)$ as

$$
\begin{aligned}
E_{t}\left[\left(1-L^{-1}\right)\left(1-\gamma_{f} L^{-1}-\gamma_{b} L\right)-\tilde{\kappa}\left(-\sigma^{-1} \psi_{\pi}+\sigma^{-1} L^{-1}\right)\right] \pi_{t} & =E_{t}\left[\tilde{\kappa} \sigma^{-1} \psi_{\pi}\right] \pi_{t}^{*} \\
E_{t}\left[\left(1+\gamma_{b}+\tilde{\kappa} \sigma^{-1} \psi_{\pi}\right)-\left(1+\gamma_{f}+\tilde{\kappa} \sigma^{-1}\right) L^{-1}-\gamma_{b} L+\gamma_{f} L^{-2}\right] \pi_{t} & =E_{t}\left[\tilde{\kappa} \sigma^{-1} \psi_{\pi}\right] \pi_{t}^{*}
\end{aligned}
$$

We express the solution using the eigenvalues $\lambda_{1}, \lambda_{2}$, and $\lambda_{3}$ as

$$
\begin{aligned}
E_{t}\left(1-\lambda_{1} L\right)\left(\lambda_{2}-L^{-1}\right)\left(\lambda_{3}-L^{-1}\right) \pi_{t} & =\frac{\tilde{\kappa} \sigma^{-1} \psi_{\pi}}{\gamma_{f}} \pi_{t}^{*} \\
\left(1-\lambda_{1} L\right) \pi_{t} & =E_{t} \frac{\tilde{\kappa} \sigma^{-1} \psi_{\pi}}{\gamma_{f}}\left(\lambda_{2}-L^{-1}\right)^{-1}\left(\lambda_{3}-L^{-1}\right)^{-1} \pi_{t}^{*} \\
\left(1-\lambda_{1} L\right) \pi_{t} & =\frac{\tilde{\kappa} \sigma^{-1} \psi_{\pi}}{\gamma_{f}} \frac{1}{\lambda_{2}-\phi_{\pi^{*}}} \frac{1}{\lambda_{3}-\phi_{\pi^{*}}} \pi_{t}^{*}
\end{aligned}
$$

The solution for $\pi_{t}$ is then given by

$$
\pi_{t}=\frac{1}{\lambda_{2}-\phi_{\pi^{*}}} \frac{1}{\lambda_{3}-\phi_{\pi^{*}}} \frac{\psi_{\pi} \kappa \sigma^{-1}}{\beta} \pi_{t}^{*}+\lambda_{1} \pi_{t-1}
$$

Lemma $30<\lambda_{1}<1$.

Proof. We start with Lemma 1. It shows $\left|\lambda_{1}\right|<1$ to ensure determinacy in (A.17). We will further show $\lambda_{1}>0$. Suppose $\lambda_{1}<0$. Since $\lambda_{1} \lambda_{2} \lambda_{3}>0$ from (A.15) and $\left|\lambda_{1}\right|<1$, it requires that $\lambda_{2} \lambda_{3}<0$. We know that $\lambda_{1} \lambda_{2}+\lambda_{2} \lambda_{3}+\lambda_{3} \lambda_{1}=\lambda_{1}\left(\lambda_{2}+\lambda_{3}\right)+\lambda_{2} \lambda_{3}>0$ from (A.14). 
Since $\lambda_{1}<0$ and $\lambda_{2} \lambda_{3}<0$, it requires that $\lambda_{2}+\lambda_{3}<0$. However, it contradicts the fact that $\lambda_{1}+\lambda_{2}+\lambda_{3}>0$ from (A.16). In addition, since $\lambda_{1} \lambda_{2} \lambda_{3}>0$, it requires that $\lambda_{1} \neq 0$. Therefore, it must be $\lambda_{1}>0$. In combination with Lemma 1, we can show that $0<\lambda_{1}<1$.

Lemma $4 \lambda_{2}>1$ and $\lambda_{3}>1$.

Proof. We again start with Lemma 1. Because $\lambda_{1}+\lambda_{2}+\lambda_{3}=\frac{1+\gamma_{f}+\tilde{\kappa} \sigma^{-1}}{\gamma_{f}}=1+\frac{1+\tilde{\kappa} \sigma^{-1}}{\gamma_{f}}>1$ and $0<\lambda_{1}<1$, it requires that $\lambda_{2}+\lambda_{3}>0$. In addition, because $\lambda_{1} \lambda_{2} \lambda_{3}>0$ and $0<\lambda_{1}<1$, it requires that $\lambda_{2} \lambda_{3}>0$. Then, because $\lambda_{2}+\lambda_{3}>0$ and $\lambda_{2} \lambda_{3}>0$, it requires that $\lambda_{2}>0$ and $\lambda_{3}>0$. In combination with $\left|\lambda_{1}\right|<1<\left|\lambda_{2}\right| \leq\left|\lambda_{3}\right|$, we can show that $\lambda_{2}>1$ and $\lambda_{3}>1$.

Lemma 5 As $\psi_{\pi} \rightarrow \infty, \lambda_{1} \rightarrow 0$ and $\lambda_{1} \psi_{\pi} \rightarrow \frac{\tau}{\kappa \sigma^{-1}}$.

Proof. Note that the solution for strict inflation targeting with the hybrid NKPC (i.e., $\left.\psi_{\pi} \rightarrow \infty\right)$ is given by $\pi_{t}=\pi_{t}^{*}$. From (A.26) in Lemma 1, it requires that $\lim _{\psi_{\pi} \rightarrow \infty} \Phi_{1}=0$ and $\lim _{\psi_{\pi} \rightarrow \infty} \Phi_{0}=1$. Note that $\Phi_{1}=\lambda_{1}$. Therefore, $\lim _{\psi_{\pi} \rightarrow \infty} \lambda_{1}=0$.

Now, we consider $\lim _{\psi_{\pi} \rightarrow \infty} \Phi_{0}=1$. Note that $\Phi_{0}=\frac{1}{\left(\lambda_{2}-\phi_{\pi^{*}}\right)\left(\lambda_{3}-\phi_{\pi^{*}}\right)} \frac{\psi_{\pi} \kappa \sigma^{-1}}{\beta}$. Because $\lim _{\psi_{\pi} \rightarrow \infty} \Phi_{0}=1$, it requires that

$$
\lim _{\psi_{\pi} \rightarrow \infty} \frac{1}{\left(\lambda_{2}-\phi_{\pi^{*}}\right)\left(\lambda_{3}-\phi_{\pi^{*}}\right)} \frac{\psi_{\pi} \kappa \sigma^{-1}}{\beta}=1
$$

where

$$
\begin{aligned}
& \frac{1}{\left(\lambda_{2}-\phi_{\pi^{*}}\right)} \frac{1}{\left(\lambda_{3}-\phi_{\pi^{*}}\right)} \frac{\psi_{\pi} \kappa \sigma^{-1}}{\beta} \\
= & \frac{1}{\lambda_{2} \lambda_{3}-\phi_{\pi^{*}}\left(\lambda_{2}+\lambda_{3}\right)+\phi_{\pi^{*}}^{2}} \frac{\psi_{\pi} \kappa \sigma^{-1}}{\beta} \\
= & \frac{1}{\frac{\tau}{\lambda_{1} \beta}-\phi_{\pi^{*}}\left(\frac{1+\beta \tau}{\beta}-\lambda_{1}\right)+\phi_{\pi^{*}}^{2}} \frac{\psi_{\pi} \kappa \sigma^{-1}}{\beta} \\
= & \frac{\lambda_{1} \psi_{\pi}}{\frac{\tau}{\beta}-\lambda_{1} \phi_{\pi^{*}} \frac{1+\beta \tau}{\beta}+\lambda_{1}^{2} \phi_{\pi^{*}}+\lambda_{1} \phi_{\pi^{*}}^{2}} \frac{\kappa \sigma^{-1}}{\beta} .
\end{aligned}
$$

Because $\lim _{\psi_{\pi} \rightarrow \infty} \lambda_{1}=0$, it requires $\lim _{\psi_{\pi} \rightarrow \infty} \lambda_{1} \psi_{\pi}=\frac{\tau}{\kappa \sigma^{-1}}$. We will confirm theses conditions in the case of the solutions for $i_{t}$ in Lemma 6 . 


\section{Proof of Proposition 1}

Proof. We first show that inflation increases in the inflation target. In Lemma $2, \Phi_{1}$ is always positive because $\Phi_{1}=\lambda_{1}$ and $0<\lambda_{1}<1$ from Lemma 3. In addition, because $\lambda_{2}>1$ and $\lambda_{3}>1$ in Lemma $4, \Phi_{0}$ is always positive. Thus, inflation always increases when the monetary authority raises the inflation target.

Now, we consider the response of the nominal interest rate to the change in the inflation target. Inflation always increases in the inflation target and so should the nominal interest rate. Lemma 1 shows that the solution for $i_{t}$ to the New Keynesian model is given by

$$
i_{t}=\Gamma_{0} \pi_{t}^{*}+\Gamma_{1} \pi_{t-1}
$$

where

$$
\begin{aligned}
\Gamma_{0}= & \frac{1}{\lambda_{2}-\phi_{\pi^{*}}} \frac{1}{\lambda_{3}-\phi_{\pi^{*}}} \frac{\psi_{\pi} \kappa \sigma^{-1}}{\beta} \times \\
& \left\{\phi_{\pi^{*}}-\frac{\left(1-\phi_{\pi^{*}}\right)\left(1-\beta \phi_{\pi^{*}}\right)+\left\{1+\beta\left(1-\phi_{\pi^{*}}\right)\right\} \tau}{\kappa \sigma^{-1}}+\frac{\tau}{\kappa \sigma^{-1}}\left(\frac{\lambda_{2}+\lambda_{3}-\phi_{\pi^{*}}}{\lambda_{2} \lambda_{3}}\right)\right\}, \\
\Gamma_{1}= & \psi_{\pi} \lambda_{1} .
\end{aligned}
$$

Because $0<\lambda_{1}<1$ in Lemma 3, $\Gamma_{1}$ is always positive. In order for the model to exhibit the comovement between inflation and the nominal interest rate, $\Gamma_{0}$ should be positive. Thus, we will find the condition for $\Gamma_{0}>0$. Lemma 4 shows that $\lambda_{2}>1$ and $\lambda_{3}>1$ and it implies that the scaling factor in $\Gamma_{0}, \frac{1}{\lambda_{2}-\phi_{\pi^{*}}} \frac{1}{\lambda_{3}-\phi_{\pi^{*}}} \frac{\psi_{\pi} \kappa \sigma^{-1}}{\beta}$, is always positive because $0<\phi_{\pi^{*}}<1$ and other structural parameters are positive. Therefore, the sign of $\Gamma_{0}$ depends on the sign of

$$
\Omega=\phi_{\pi^{*}}-\frac{\left(1-\phi_{\pi^{*}}\right)\left(1-\beta \phi_{\pi^{*}}\right)}{\kappa \sigma^{-1}}-\frac{\tau}{\kappa \sigma^{-1}}\left\{1+\beta\left(1-\phi_{\pi^{*}}\right)\right\}+\frac{\tau}{\kappa \sigma^{-1}}\left(\frac{\lambda_{2}+\lambda_{3}-\phi_{\pi^{*}}}{\lambda_{2} \lambda_{3}}\right)
$$

We want to find how $\psi_{\pi}$ affects the role of the backward-looking component in breaking down Neo-Fisherism. Note that eigenvalues $\lambda_{2}$ and $\lambda_{3}$ are functions of the model parameters 
including $\tau$ and $\psi_{\pi}$ and

$$
\begin{aligned}
\frac{\lambda_{2}+\lambda_{3}-\phi_{\pi^{*}}}{\lambda_{2} \lambda_{3}} & =\frac{\frac{1+\gamma_{f}+\tilde{\kappa} \sigma^{-1}}{\gamma_{f}}-\lambda_{1}-\phi_{\pi^{*}}}{\frac{\gamma_{b}}{\gamma_{f} \lambda_{1}}} \\
& =\frac{\left(1+\gamma_{f}+\tilde{\kappa} \sigma^{-1}\right) \lambda_{1}-\gamma_{f} \lambda_{1}^{2}-\gamma_{f} \phi_{\pi^{*}} \lambda_{1}}{\gamma_{b}} \\
& =\frac{\left(1+\beta \tau+\beta+\kappa \sigma^{-1}\right) \lambda_{1}-\beta \lambda_{1}^{2}-\beta \phi_{\pi^{*}} \lambda_{1}}{\tau} \\
& =\frac{\beta \lambda_{1}\left(1-\lambda_{1}\right)+\left\{\beta \tau+\kappa \sigma^{-1}+\left(1-\phi_{\pi^{*}} \beta\right)\right\} \lambda_{1}}{\tau} \\
& =\frac{\lambda_{1}\left\{\beta\left(1-\lambda_{1}\right)+\beta \tau+\kappa \sigma^{-1}+\left(1-\phi_{\pi^{*}} \beta\right)\right\}}{\tau} .
\end{aligned}
$$

Because $0<\lambda_{1}<1$,

$$
\frac{\lambda_{2}+\lambda_{3}-\phi_{\pi^{*}}}{\lambda_{2} \lambda_{3}}>0
$$

It implies that as $\frac{\lambda_{2}+\lambda_{3}-\phi_{\pi^{*}}}{\lambda_{2} \lambda_{3}}$ gets smaller, $\Omega$ in (A.36) gets smaller.

In addition, from the fact that $\lim _{\psi_{\pi} \rightarrow \infty} \lambda_{1}=0$ in Lemma 5 and the equation in (A.37), we can show that

$$
\lim _{\psi_{\pi} \rightarrow \infty} \frac{\lambda_{2}+\lambda_{3}-\phi_{\pi^{*}}}{\lambda_{2} \lambda_{3}}=0
$$

Therefore, under strict inflation targeting (i.e., $\left.\psi_{\pi} \rightarrow \infty\right) \Omega$ is the smallest and the model is the least likely to exhibit Neo-Fisherism.

Lemma 6 As $\psi_{\pi} \rightarrow \infty$, the solution for $i_{t}$ in the model with the Taylor-type rule approaches that in the model with strict inflation targeting.

Proof. Now, we confirm our conditions in the case of the solutions for $i_{t}$. Under strict inflation targeting, Garín, Lester and Sims (2018) show that

$$
i_{t}=\left[\phi_{\pi^{*}}-\frac{\left(1-\phi_{\pi^{*}}\right)\left(1-\beta \phi_{\pi^{*}}\right)}{\kappa \sigma^{-1}}-\frac{\tau}{\kappa \sigma^{-1}}\left\{1+\beta\left(1-\phi_{\pi^{*}}\right)\right\}\right] \pi_{t}^{*}+\frac{\tau}{\kappa \sigma^{-1}} \pi_{t-1}^{*}
$$

We will show $\lim _{\psi_{\pi} \rightarrow \infty} \Gamma_{0}=\left[\phi_{\pi^{*}}-\frac{\left(1-\phi_{\pi^{*}}\right)\left(1-\beta \phi_{\pi^{*}}\right)}{\kappa \sigma^{-1}}-\frac{\tau}{\kappa \sigma^{-1}}\left\{1+\beta\left(1-\phi_{\pi^{*}}\right)\right\}\right]$ and $\lim _{\psi_{\pi} \rightarrow \infty} \Gamma_{1}=$ $\frac{\tau}{\kappa \sigma^{-1}}$. Because $\Gamma_{1}=\lambda_{1} \psi_{\pi}$, it is straightforward to show that $\lim _{\psi_{\pi} \rightarrow \infty} \Gamma_{1}=\frac{\tau}{\kappa \sigma^{-1}}$ from 
Lemma 5. Further, because

$$
\begin{aligned}
& \Gamma_{0}=\frac{1}{\lambda_{2}-\phi_{\pi^{*}}} \frac{1}{\lambda_{3}-\phi_{\pi^{*}}} \frac{\psi_{\pi} \kappa \sigma^{-1}}{\beta} \\
& \times\left[\phi_{\pi^{*}}-\frac{\left(1-\phi_{\pi^{*}}\right)\left(1-\beta \phi_{\pi^{*}}\right)}{\kappa \sigma^{-1}}-\frac{\tau}{\kappa \sigma^{-1}}\left\{1+\beta\left(1-\phi_{\pi^{*}}\right)\right\}+\frac{\tau}{\kappa \sigma^{-1}}\left(\frac{\lambda_{2}+\lambda_{3}-\phi_{\pi^{*}}}{\lambda_{2} \lambda_{3}}\right)\right],
\end{aligned}
$$

$\lim _{\psi_{\pi} \rightarrow \infty} \frac{1}{\left(\lambda_{2}-\phi_{\pi^{*}}\right)\left(\lambda_{3}-\phi_{\pi^{*}}\right)} \frac{\psi_{\pi} \kappa \sigma^{-1}}{\beta}=1$, and $\lim _{\psi_{\pi} \rightarrow \infty} \frac{\lambda_{2}+\lambda_{3}-\phi_{\pi^{*}}}{\lambda_{2} \lambda_{3}}=0$, it is straightforward to show that $\lim _{\psi_{\pi} \rightarrow \infty} \Gamma_{0}=\left[\phi_{\pi^{*}}-\frac{\left(1-\phi_{\pi^{*}}\right)\left(1-\beta \phi_{\pi^{*}}\right)}{\kappa \sigma^{-1}}-\frac{\tau}{\kappa \sigma^{-1}}\left\{1+\beta\left(1-\phi_{\pi^{*}}\right)\right\}\right]$.

\section{Proof of Proposition 2}

Proof. Following a similar approach in Proposition 1, we find that the solution for $i_{t}$ to the New Keynesian model with (4), (5), and (11) is given by

$$
\begin{aligned}
i_{t}= & \psi_{\pi} \tilde{\lambda}_{1} \pi_{t-1}+\frac{1}{\tilde{\lambda}_{2}-\phi_{\pi^{*}}} \frac{1}{\tilde{\lambda}_{3}-\phi_{\pi^{*}}} \frac{\psi_{\pi} \kappa \sigma^{-1}(1-h)}{\beta} \times \\
& \left\{\phi_{\pi^{*}}-\frac{\left(1-\phi_{\pi^{*}}+h\right)\left(1-\beta \phi_{\pi^{*}}\right)}{\kappa \sigma^{-1}(1-h)}+\frac{h}{\kappa \sigma^{-1}(1-h)}\left(\frac{\tilde{\lambda}_{2}+\tilde{\lambda}_{3}-\phi_{\pi^{*}}}{\tilde{\lambda}_{2} \tilde{\lambda}_{3}}\right)\right\} \pi_{t}^{*}
\end{aligned}
$$

where $\tilde{\lambda}_{1}, \tilde{\lambda}_{2}$, and $\tilde{\lambda}_{3}$ are eigenvalues associated with the solution, $0<\tilde{\lambda}_{1}<1, \tilde{\lambda}_{2}>1$, and $\tilde{\lambda}_{3}>1 .^{19}$

Again, taking the same approach in Proposition 1, we can show that

$$
\frac{\tilde{\lambda}_{2}+\tilde{\lambda}_{3}-\phi_{\pi^{*}}}{\tilde{\lambda}_{2} \tilde{\lambda}_{3}}>0
$$

and

$$
\lim _{\psi_{\pi} \rightarrow \infty} \frac{\tilde{\lambda}_{2}+\tilde{\lambda}_{3}-\phi_{\pi^{*}}}{\tilde{\lambda}_{2} \tilde{\lambda}_{3}}=0 .
$$

Therefore, under strict inflation targeting the model is the least likely to exhibit NeoFisherism.

Regarding the impulse response function of inflation to the inflation target shock, we

\footnotetext{
${ }^{19}$ They can be shown by taking similar approaches in Lemmas 3 and 4.
} 
take the same approach in Lemma 2. The solution for $\pi_{t}$ is then given by

$$
\pi_{t}=\tilde{\lambda}_{1} \pi_{t-1}+\frac{1}{\tilde{\lambda}_{2}-\phi_{\pi^{*}}} \frac{1}{\tilde{\lambda}_{3}-\phi_{\pi^{*}}} \frac{\psi_{\pi} \kappa \sigma^{-1}(1-h)}{\beta} \pi_{t}^{*}
$$

Because $0<\tilde{\lambda}_{1}<1, \tilde{\lambda}_{2}>1$, and $\tilde{\lambda}_{3}>1$, the coefficients on $\pi_{t-1}$ and $\pi_{t}^{*}$ in (A.43) are both positive. Therefore, inflation always increases in the inflation target. All the details on the proof are available upon request.

\section{B The Smets and Wouters (2007) model}

This appendix briefly describes the medium-scale model in Smets and Wouters (2007), which we use in Section 3 in the main text. The model features sticky nominal price and wage settings, capital formation with investment adjustment costs, and variable capital utilization. The backward-looking behaviour is present in the household sector via habit formation, wage indexation, and investment adjustment costs and in the intermediate-goods sector through a backward price indexation. Aggregate fluctuations are driven by seven exogenous shocks: total factor productivity (TFP), risk-premium, investment-specific technology, wage markup, price mark-up, government spending, and monetary policy shocks. The central bank conducts monetary policy through a Taylor-type rule. In order to investigate the effect of changes in the inflation target, we augment the Smets and Wouters model with an exogenous inflation target shock process.

The model is log-linearized around the steady state or the balanced growth path with deterministic labor-augmenting technology, which we summarize below. We follow the variable and parameter naming convention used in Smets and Wouters (2007). The variables in the model are (in deviations from the deterministic trend): $\widehat{m c}_{t}$ real marginal cost; $\hat{z}_{t}$ capital utilization rate; $\hat{r}_{t}^{k}$ rental rate of capital; $\widehat{\bar{k}}_{t}$ physical capital; $\hat{k}_{t}$ effective capital; $\hat{Q}_{t}$ unit price of capital; $\hat{c}_{t}$ consumption; $\widehat{i}_{t}$ investment; $\hat{y}_{t}$ output; $\hat{L}_{t}$ labor; $\hat{w}_{t}$ real wage; $\hat{r}_{t}$ nominal interest rate; $\hat{\pi}_{t}$ inflation. The exogenous variables (with the i.i.d. shocks in the parenthesis) are: $\hat{\varepsilon}_{t}^{a}\left(\eta_{t}^{a}\right)$ exogenous TFP; $\hat{\varepsilon}_{t}^{b}\left(\eta_{t}^{b}\right)$ risk premium; $\hat{\varepsilon}_{t}^{g}\left(\eta_{t}^{g}\right)$ government spending; $\hat{\varepsilon}_{t}^{i}\left(\eta_{t}^{i}\right)$ investment-specific technology; $\hat{\varepsilon}_{t}^{r}\left(\eta_{t}^{r}\right)$ monetary policy; $\hat{\varepsilon}_{t}^{p}\left(\eta_{t}^{p}\right)$ price mark-up; $\hat{\varepsilon}_{t}^{w}\left(\eta_{t}^{w}\right)$ wage 
Table B.1: Calibration of the Smets and Wouters model

\begin{tabular}{lll}
\hline Parameter & Value & Description \\
\hline $100(\gamma-1)$ & 0.44 & trend productivity growth \\
$\sigma$ & 1.47 & inverse of elasticity of intertemporal substitution \\
$h$ & 0.68 & degree of external habit \\
$\beta$ & 0.9987 & subjective discount factor \\
$\nu_{l}$ & 2.30 & labor supply elasticity parameter \\
$\alpha$ & 0.21 & capital share of production \\
$\varsigma_{w}$ & 0.46 & degree of wage indexation \\
$\varsigma_{p}$ & 0.21 & degree of price indexation \\
$\xi_{w}$ & 0.74 & probability of wage fixity \\
$\xi_{p}$ & 0.73 & probability of price fixity \\
$\psi$ & 0.69 & variable utilization cost parameter \\
$\delta$ & 0.025 & capital depreciation rate \\
$\Phi$ & 1.54 & fixed cost of production \\
$S^{\prime \prime}=\varphi$ & 6.23 & steady-state elasticity of investment adjustment cost \\
$\bar{\phi}$ & 0.67 & steady-state quarterly inflation \\
$\rho$ & 0.84 & Taylor-rule interest rate smoothing parameter \\
$r_{\pi}$ & 1.77 & Taylor-rule inflation feedback coefficient \\
$r_{y}$ & 0.08 & Taylor-rule output gap feedback coefficient \\
$r_{\Delta y}$ & 0.16 & Taylor-rule change in output gap feedback coefficient \\
\hline
\end{tabular}

mark-up; $\hat{\pi}_{t}^{*}\left(\hat{\varepsilon}_{\pi^{*}, t}\right)$ inflation target. We calibrate the model to the U.S. economy using the posterior mode estimates reported in Smets and Wouters (2007) for the sample period of 1984Q1-2004Q4 (see their Table 5). These values are presented in Table B.1 for convenience.

\section{Log-linearized equations}

The log-linearized equations in the model are presented below.

Real marginal cost:

$$
\widehat{m c}_{t}=\alpha \hat{r}_{t}^{k}+(1-\alpha) \hat{w}_{t}-\varepsilon_{t}^{a}
$$

Rate of capacity utilisation:

$$
\hat{z}_{t}=z_{1} \hat{r}_{t}^{k}
$$

where $z_{1} \equiv(1-\psi) / \psi$. 
Optimal capital-labor ratio:

$$
\hat{r}_{t}^{k}=\hat{w}_{t}+\hat{L}_{t}-\hat{k}_{t}
$$

Link between physical capital, capital utilization, and effective capital:

$$
\hat{k}_{t}=\widehat{\bar{k}}_{t-1}+\hat{z}_{t}
$$

Investment Euler equation:

$$
\widehat{i}_{t}=\frac{1}{(1+\bar{\beta} \gamma)}\left[\widehat{i}_{t-1}+\bar{\beta} \gamma E_{t} \widehat{i}_{t+1}+\frac{1}{\gamma^{2} S^{\prime \prime}} \hat{Q}_{t}\right]+\hat{\varepsilon}_{t}^{i}
$$

where $\bar{\beta} \equiv \beta \gamma^{-\sigma}$.

Unit price of capital: equation (16) in the main text.

Capital accumulation:

$$
\widehat{\bar{k}}_{t}=\left(1-\frac{\bar{l}}{\bar{k}}\right) \widehat{\bar{k}}_{t-1}+\frac{\bar{\imath}}{\bar{k}} \hat{\mu}_{t}+\frac{\bar{\imath}}{\bar{k}} \widehat{i}_{t}
$$

where $\frac{\bar{\imath}}{k}$ is the steady-state investment to capital ratio and $\hat{\mu}_{t}$ is a reduced-form investmentspecific technology shock (a function of $\varepsilon_{t}^{i}$ ).

Consumption Euler equation: equation (15) in the main text.

Aggregate resource constraint:

$$
\hat{y}_{t}=\left(\frac{\bar{c}}{\bar{y}}\right) \hat{c}_{t}+\left(\frac{\bar{\imath}}{\bar{y}}\right) \hat{i}_{t}+\left(\frac{\bar{r}^{k} \bar{k}}{\bar{y}}\right) \hat{z}_{t}+\hat{\varepsilon}_{t}^{g}
$$

where $\frac{\bar{c}}{\bar{y}}, \frac{\bar{l}}{\bar{y}}, \frac{\bar{r}^{k} \bar{k}}{\bar{y}}$ denote the steady-state consumption to output ratio, investment to output ratio, and capital rental income to output ratio.

Aggregate production function:

$$
\hat{y}_{t}=\left(\frac{\bar{y}+\Phi}{\bar{y}}\right)\left[\alpha \hat{k}_{t}+(1-\alpha) \hat{L}_{t}+\varepsilon_{t}^{a}\right]
$$


Price Phillips curve:

$$
\hat{\pi}_{t}=\left[\frac{\varsigma_{p}}{1+\bar{\beta} \gamma \varsigma_{p}}\right] \hat{\pi}_{t-1}+\left[\frac{\bar{\beta} \gamma}{1+\bar{\beta} \gamma \varsigma_{p}}\right] E_{t} \hat{\pi}_{t+1}+\kappa_{p} \widehat{m c}_{t}+\hat{\varepsilon}_{t}^{p}
$$

where $\kappa_{p} \equiv A \frac{\left(1-\xi_{p} \bar{\beta} \gamma\right)\left(1-\xi_{p}\right)}{\left(1+\bar{\beta} \gamma_{p}\right) \xi_{p}} . A$ is a reduced-form parameter that depends on the consumption aggregator function.

Wage Phillips curve:

$$
\begin{aligned}
\hat{w}_{t}= & {\left[\frac{1}{1+\bar{\beta} \gamma}\right] \hat{w}_{t-1}+\left[\frac{\bar{\beta} \gamma}{1+\bar{\beta} \gamma}\right] E_{t} \hat{w}_{t+1} } \\
& +\frac{1}{1+\bar{\beta} \gamma}\left[-\left(1+\bar{\beta} \gamma \varsigma_{w}\right) \hat{\pi}_{t}+\varsigma_{w} \hat{\pi}_{t-1}+\bar{\beta} \gamma E_{t} \hat{\pi}_{t+1}\right] \\
& +\kappa_{w}\left[\frac{1}{1-h / \gamma} \hat{c}_{t}-\frac{h / \gamma}{1-h / \gamma} \hat{c}_{t-1}+\nu_{l} \hat{L}_{t}-\hat{w}_{t}\right] \\
& +\hat{\varepsilon}_{t}^{w},
\end{aligned}
$$

where $\kappa_{w} \equiv \frac{\left(1-\xi_{w} \bar{\gamma} \gamma\right)\left(1-\xi_{w}\right)}{(1+\bar{\beta} \gamma) \xi_{w}}$.

Monetary policy rule: equation (13) in the main text.

Inflation target shock process: equation (12) in the main text.

\section{Smets and Wouters model: Further results on the comovement under alternative parameterizations}

In this appendix, we investigate how the Neo-Fisherian property in the Smets and Wouters model is affected by the Calvo price parameter $\xi_{p}$, which governs the degree of price stickiness and the NKPC slope, and the EIS $\sigma^{-1}$, similar to what we do for the small-scale model in Section 2.

As shown in Panel (a) of Figure C.1, a higher Calvo price parameter $\left(\xi_{p}=0.85\right)$ makes a positive comovement less likely. In the benchmark case of $\xi_{p}=0.73$, the nominal interest rates increase by more throughout the periods. This result is consistent with that in the small-scale New Keynesian model in Section 2 (see Figure 4). Still, even with a flatter price Phillips curve under $\xi_{p}=0.85$, the SW model exhibits Neo-Fisherism. 
Figure C.1: Smets and Wouters model: Comovement between inflation and the nominal interest rate for different values of selective parameters (further results)
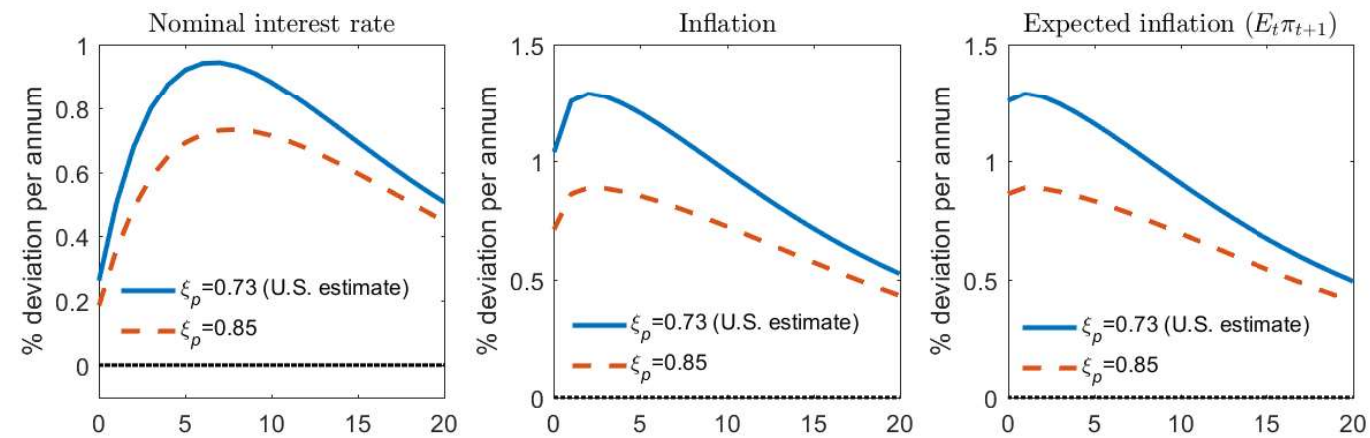

(a) Calvo price parameter
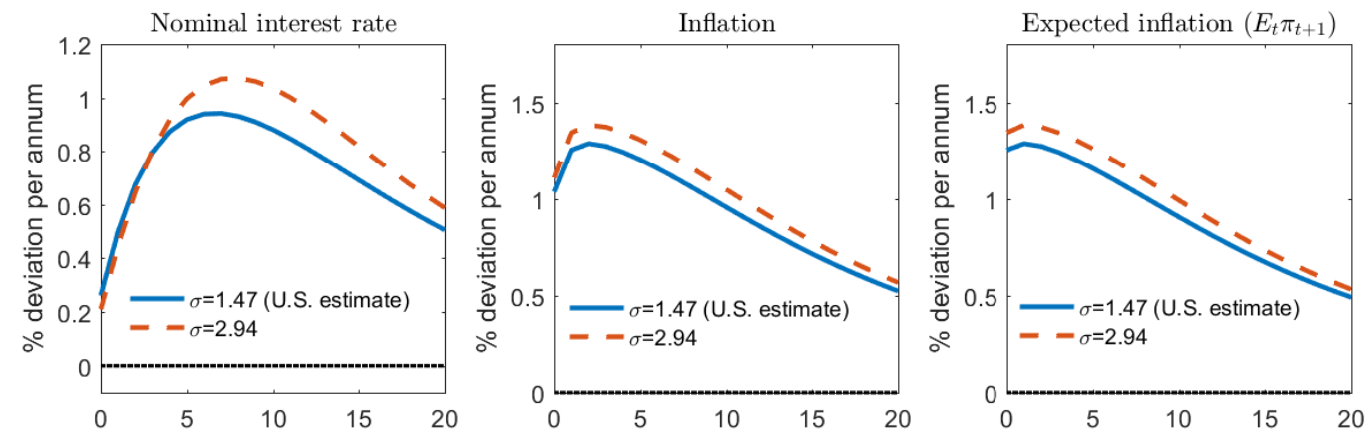

(b) Intertemporal substitution parameter

Note: The size of the inflation target shock in all cases is $1 \%$ per annum at period 0 with $\phi_{\pi^{*}}=0.95$. All other parameter values are based on the posterior mode estimates for the sample period of 1984Q1-2004Q4 in Smets and Wouters (2007).

In Panel (b) of Figure C.1, we consider two values of $\sigma$ : the posterior estimate based on the U.S. data $(\sigma=1.47)$ and twice of that $(\sigma=2.94)$. The latter case thus implies a lower EIS. Consistent with Figure 5 in Section 2, a lower elasticity makes a positive comovement less likely. Here, for example, the nominal rate increases by less on impact when $\sigma=2.94$. It appears, however, that this parameter does not significantly affect the Neo-Fisherian property in the SW model, as is apparent from the similar responses across the two different values of $\sigma$. Both parameterizations imply a positive comovement between inflation and the nominal rate. 